\title{
Review Article \\ Recent Development of Catalytic Materials for Ethylbenzene Oxidation
}

\author{
Md. Motiar Rahman $\mathbb{D D}^{1}{ }^{1}$ Mst. Gulshan Ara, ${ }^{2}$ Md. Sohanur Rahman, ${ }^{2}$ Md. Sahab Uddin $\mathbb{D}^{3,4}$ \\ May N. Bin-Jumah $(1),{ }^{5}$ and Mohammed M. Abdel-Daim $\mathbb{1}^{6,7}$ \\ ${ }^{1}$ Institute of Synthetic Biology, Shenzhen Institute of Advanced Technology (SIAT), Chinese Academy of Sciences (CAS), \\ Shenzhen 518055, China \\ ${ }^{2}$ Graduate School of Innovative Life Science, University of Toyama, Gofuku 3190, Toyama 930-8555, Japan \\ ${ }^{3}$ Department of Pharmacy, Southeast University, Dhaka, Bangladesh \\ ${ }^{4}$ Pharmakon Neuroscience Research Network, Dhaka, Bangladesh \\ ${ }^{5}$ Department of Biology, College of Science, Princess Nourah Bint Abdulrahman University, Riyadh 11474, Saudi Arabia \\ ${ }^{6}$ Department of Zoology, College of Science, King Saud University, P.O. Box 2455, Riyadh 11451, Saudi Arabia \\ ${ }^{7}$ Pharmacology Department, Faculty of Veterinary Medicine, Suez Canal University, Ismailia 41522, Egypt
}

Correspondence should be addressed to Md. Motiar Rahman; motiar_bio@yahoo.com

Received 13 November 2019; Accepted 26 December 2019; Published 25 February 2020

Guest Editor: Domenico Lombardo

Copyright (c) $2020 \mathrm{Md}$. Motiar Rahman et al. This is an open access article distributed under the Creative Commons Attribution License, which permits unrestricted use, distribution, and reproduction in any medium, provided the original work is properly cited.

Catalysts are well-known to convert alkylbenzenes at high thermal condition to a number of useful products. However, the current schemes of transformation are not suitable for the hazard-free industrial applications because their reactive intermediates are transformed to a variety of side products that often retard the optimum yield and cause environmental pollutions. It is also observed that the formation of products depends on a wide range of parameters which are extremely difficult to control and often incur extra cost. Recently, heterogeneous catalysts have received huge commercial interests for the oxidation of alkylbenzene into carbonyl compounds which are platform chemicals in various synthetics and fine chemicals. This review is an up-to-date documentary on various catalysts used for the oxidation of alkyl-substituted benzenes along with their reaction condition and selectivity profiles. This work updates our knowledge for the selection and/or design of novel catalysts for the chemists and engineers in the industrial and academic settings.

\section{Introduction}

The oxidations of hydrocarbons to its corresponding carbonyl group (aldehydes or ketones) have a substantial value in organic synthesis, both in laboratory and in industry $[1,2]$. It is remarkable to note that the global production of carbonyl composites per year has exceeded $10^{7}$ tones and many of these are produced from the direct oxidation of hydrocarbons [3]. In this regard, the catalyst-assisted oxidation processes have made significant contributions in the production of various chemicals, cosmetics, drugs, and other useful compounds. Among the various substrates used in oxidation reactions, aryl alkanes, such as ethylbenzene, have huge interests because their essential oxidation products are a rich source of a number of drugs and synthetics. For example, the oxidation products of ethylbenzene such as acetophenone and 1-phenylethanol are the precursors of optically active alcohols [4], benzalacetophenones (chalcones) [5, 6], and hydrazones [7].

The oxidation process was traditionally carried out by a stoichiometric amount of oxidants such as permanganates $[8,9]$, chromium reagents [10-13], ruthenium (VIII) oxide $[14,15]$, activated dimethyl sulfoxide (DMSO) [16] or Dess-Martin periodinane [17], and TPAP/NMO (tetra- $\mathrm{N}$ propylammonium perruthenate $/ N$-methyl-morpholine- $N$ oxide) [18], and all these involve high temperature and/or pressure and corrosive and toxic chemicals and produce 


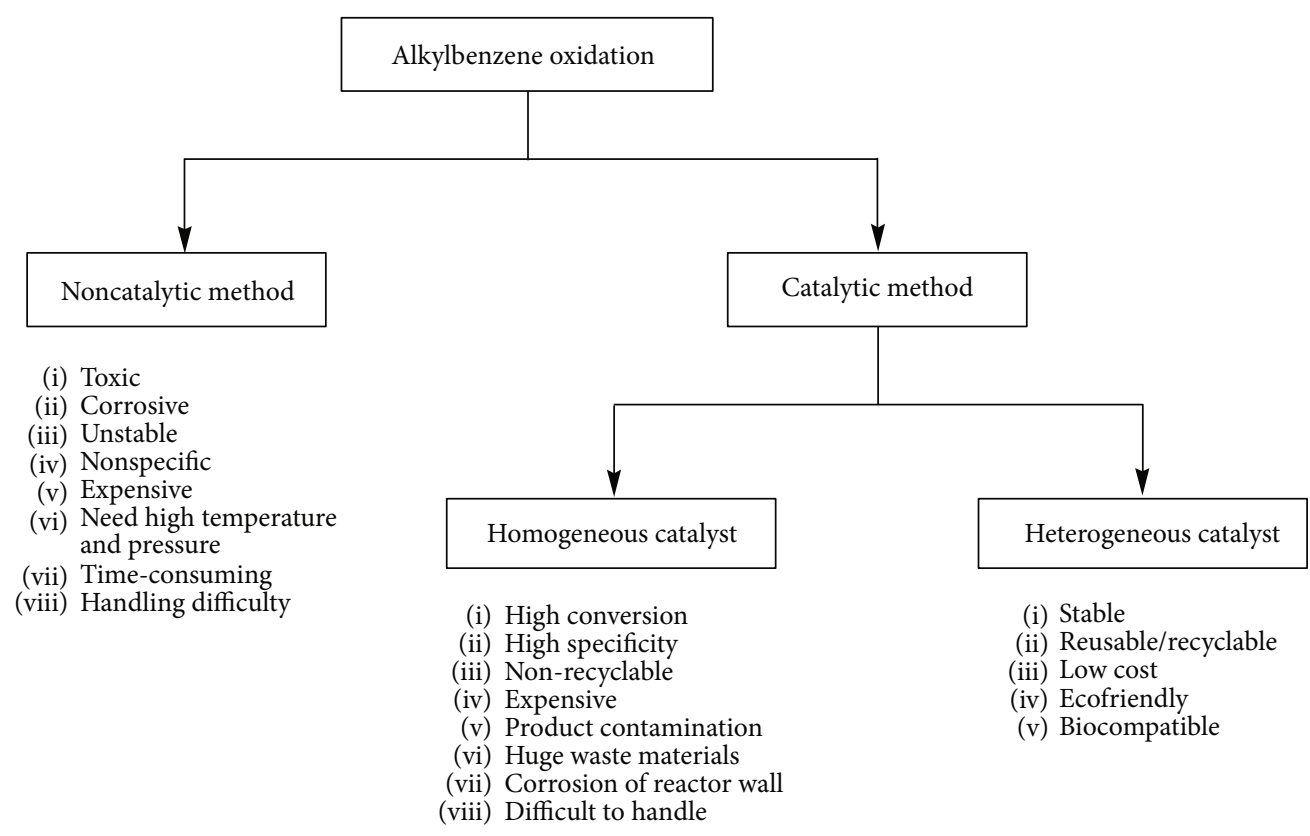

FIGURE 1: Major approaches to alkylbenzene oxidation.

an equivalent amount of waste metals, incurring the environmental burden such as halogenated organic solvents (hydrocarbons) [19, 20]. On the other hand, noncatalytic transformation under supercritical conditions [21] is immature and unsuitable commercial application due to the lack of stability and selectivity (Figure 1).

Therefore, the catalytic approaches which offer low temperature and more selective conversion, minimizing the uses and/or formation of undesirable byproducts, have evolved as the method of choice for hydrocarbon oxidation using air or clean molecular oxygen $\left(\mathrm{O}_{2}\right)$ as oxygen source (Scheme 1) [21]. Hydrogen peroxide $\left(\mathrm{H}_{2} \mathrm{O}_{2}\right)$ and tert-butyl hydroperoxide (TBHP) could also be used as oxygen source due to its obvious advantages in oxidation reaction $[22,23]$. The aim of this review is to provide a brief but comprehensive outline of the major catalytic approaches for alkylbenzene oxidation along with some other oxidation reactions.

\section{Nanotechnology for Ethylbenzene Oxidation}

Nanotechnology has set immeasurable status in the oxidation of ethylbenzene. Various catalytic materials with high surface area, high surface to volume ratio, reactivity, tunable pore size, and hydrophilic and hydrophobic interfaces are promising in catalysis. Several nanometals, such as gold [23], copper [24], titanium [25], silver [26], nickel [27], manganese [28], cobalt [29] and tin [25], deposited on solid supports are suitable in oxidation reaction. Functionalized silica with homogeneous metal dispersion which prevents metal agglomeration is efficient in ethylbenzene oxidation [23]. Gold-mediated ethylbenzene oxidation perhaps initiates Au nanoparticle-based decomposition of reactive oxidant to oxidant radical species followed by two different oxidation reactions, forming ketones and secondary alcohols [23]. Moreover, nanomaterials have increased sur-

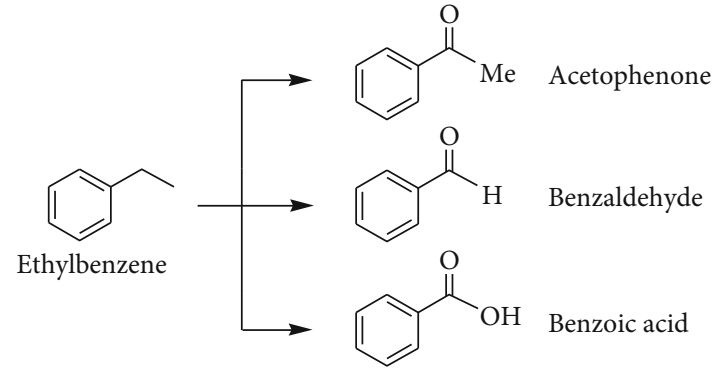

Scheme 1: Catalytic schemes for the aerobic oxidation of ethylbenzene.

face porosity that uses low free energy for the reaction to happen [30]. Nanoparticles oxidize not only ethylbenzene but also various alkanes with improved catalysis [31]. In addition, nanoparticles can activate reaction as bimetallic forms with several other metals and metal oxide with controllable shape and composition. Even though nanomaterials are appreciated in oxidation reaction, they have some limitations. Thermal instability, high-pressure requirement, metal agglomeration, pore blocking, slow reaction, poor conversion and selectivity, and the formation of side products are frequent matters in this perspective. Poor recyclability and hidden hazards to ecosystems are also leading concerns [32]. Therefore, a consistent, nontoxic, delicate, and economical oxidation process has become the most laborious task in ethylbenzene oxidation.

\section{Catalytic Method}

The major goal of using a catalyst is to speed up or accelerate the rate of a chemical reaction. It remains unchanged at the end of the reaction but minimizes the activation/free energy that is needed to attain the transition state while keeping 
the total free energy of the reactants and products unchanged in the course of the reaction $[33,34]$. The major catalytic processes for alkylbenzene oxidation are briefly presented step-by-step.

3.1. Homogeneous Catalysis. Homogeneous catalysts are those which exit in the same phase with the reactants and products; the catalysts fully dissolve in the reaction medium exposing all the catalytic sites to interact with the substrates. Homogeneous catalysts are usually complexes, often consisting of a metal which is bound to several organic ligands. The ligands are responsible for providing the stability as well as the solubility of the catalyst complex metal, and they could be adjusted to enhance selectivity of a catalyst towards the synthesis of a specific desirable product [35]. The great achievement of a homogeneous catalyst is that it can make a product with $>90 \%$ selectivity at a high conversion rate through the careful selection of the metal center, ligands, reaction parameters, and a suitable substrate [31]. Although there are widespread advantages of selectivity in homogeneous catalysis, scientists are paying enormous attention to heterogeneous catalysts; this is due to the difficulty in the separation of homogeneous catalysts. Homogeneous catalysts are also known to cause corrosion to the reaction vessels, and some of them are deposited onto the reactor wall. Thus, the workup procedure for homogeneous catalysts is not straightforward (Figure 1) [36]. Here, we represent some homogeneous catalysts used in alkylbenzene oxidation with conversion and selectivity to acetophenone (Table 1).

3.2. Heterogeneous Catalysis. Heterogeneous catalysts are those which exist in different phase from the reactants and products. They offer several advantages over their homogeneous counterparts in terms of separation and recyclability $[31,44]$. These catalysts are usually solid, but the reactants could be either solid or liquid; so they could be easily detached from the reaction mixture by simple centrifugation and washing, keeping the manufacturing cost at the minimal level. Currently, heterogeneous catalysis is dominating in industries for chemical transformation and energy generation. Approximately $90 \%$ of all industrial practices indulge in heterogeneous catalysis. The most recent applications of heterogeneous catalysts are summarized in Table 2. Consequently, scientists have drawn huge attention as the oxidation catalyst for alkylbenzene conversion with better conversion rate and higher selectivity towards ketone products which are essential intermediates for the synthesis of many specialty chemicals with high economic value such as agrochemicals, pharmaceuticals, and perfumes [45]. Herein, we describe some representative heterogeneous catalysts on various supports for ethylbenzene oxidation.

3.2.1. Nanohybrid $\mathrm{SiO}_{2} / \mathrm{Al}_{2} \mathrm{O}_{3}$ Support. Recently, the nanohybrid $\mathrm{SiO}_{2} / \mathrm{Al}_{2} \mathrm{O}_{3}$ support is used for the synthesis of various metal complexes such as Mn [28, 45, 46], Fe [47], and Co $[29,48,49]$ catalysts for catalytic oxidation of ethylbenzene (Table 3). Arshadi and Ghiaci [44] synthesized nanosized $\mathrm{SiO}_{2}-\mathrm{Al}_{2} \mathrm{O}_{3}$ mixed oxide supports and functionalized it with 3-aminopropyl-triethoxysilane (3-APTES) and 2-ami- noethyl-3-aminopropyltrimethoxysilane (2-AE-3-APTMS) linkers (Figure 2). Thus, functionalized oxide was further functionalized with Schiff base by conjugating it to $\mathrm{Mn}(\mathrm{OAc})_{2}$ to fabricate immobilized Mn catalyst complex. This heterogeneous Mn catalysts exhibited $67 \%$ ethylbenzene conversion along with $93 \%$ selectivity towards acetophenone at $80^{\circ} \mathrm{C}$ using TBHP (tert-butyl hydroperoxide) as an oxidant in the absence of any solvent. Arshadi et al. [29] further prepared Cobalt(II) Schiff base complexes immobilized onto $\mathrm{SiO}_{2}-\mathrm{Al}_{2} \mathrm{O}_{3}$ mixed oxide supports combining two diverse linkers, 3-APTES and 2-AE-3-APTMS (Figure 2). This heterogeneous Cobalt(II) complexes resulted in $86 \%$ conversion of ethylbenzene with $99 \%$ selectivity toward acetophenone.

In 2012, Arshadi et al. [46] synthesized Mn catalysts on modified $\mathrm{SiO}_{2}-\mathrm{Al}_{2} \mathrm{O}_{3}$ mixed oxide supports using 2-AE-3APTMS (Figure 3); this performed oxidation under mild conditions with a lower oxidation potential and chargetransfer resistance but leads to a greater conversion (91\%) and better selectivity (98\%) in the presence of supercritical carbon dioxide under solvent-free atmosphere. The catalysts were reused for eight times with a minimum loss of activity. In another instance, Habibi and Faraji [28] synthesized heterogeneous $\mathrm{Mn}$ nanocatalysts anchored on $\mathrm{SiO}_{2}-\mathrm{Al}_{2} \mathrm{O}_{3}$ hybrid supports using a bidentate ligand of nitrogen atoms (Figure 3). The catalysts showed remarkable activity in the oxidation of ethylbenzene (conversion rate $67 \%$ and selectivity $84 \%$ ) in the absence of any chemical solvent. On the other hand, $\mathrm{Co}$ (II) nanocatalyst was prepared by attaching of cobalt ions on inert bipyridylketone over the nanohybrid $\mathrm{SiO}_{2} / \mathrm{Al}_{2} \mathrm{O}_{3}$ mixed oxides (Figure 3) [49]. The catalytic oxidations of the prepared nanocatalyst towards ethylbenzene were assessed with TBHP as an oxidant in the absence of any solvent. Under optimal conditions, the nanocatalyst showed $79 \%$ selectivity towards the acetophenone with $47.2 \%$ conversion. Habibi and coworkers prepared another catalyst by immobilizing cobalt ion on $\mathrm{SiO}_{2}-\mathrm{Al}_{2} \mathrm{O}_{3}$ support (Figure 3) [48]. This performed ethylbenzene oxidation in $\mathrm{N}$-hydroxyphthalimide (2-hydroxy- $1 \mathrm{H}$-isoindole-1,3-dione (NHPI)) with $82 \%$ selectivity in an oxygen atmosphere and acetic acid solvent at $100^{\circ} \mathrm{C}$. Very recently, $\mathrm{SiO}_{2}-\mathrm{Al}_{2} \mathrm{O}_{3}$ APTMS-BPK-Mn(III) and $\mathrm{SiO}_{2}-\mathrm{Al}_{2} \mathrm{O}_{3}$-APTMS-BPK-Co(II) catalysts were synthesized (Figure 3); these carried out the ethylbenzene oxidation in NHPI without using any reducing agent under an oxygen atmosphere. Conversion rates were $53 \%$ and $81 \%$ with selectivities $74 \%$ and $98 \%$ towards acetophenone, respectively [45].

A novel and very simple Fe nanocatalyst on a modified nanoscale $\mathrm{SiO}_{2}-\mathrm{Al}_{2} \mathrm{O}_{3}$ (Figure 4) was studied for alkylbenzene oxidation [47]. Under optimal environments (substrate to the TBHP ratio $(1: 1)$, in the absence of solvent, at 50$120^{\circ} \mathrm{C}$ and $24 \mathrm{~h}$ reaction time), an Fe nanocatalyst exhibited $40 \%$ conversion and $89 \%$ selectivity.

3.2.2. Silica $\left(\mathrm{SiO}_{2}\right)$ Support. Silica has achieved a great interest for many catalysts; this is due to their three-dimensional open-pore network structures, high surface to volume ratio, high reusability, and distinct optoelectronic and physiochemical properties; these provide well dispersion of metal 


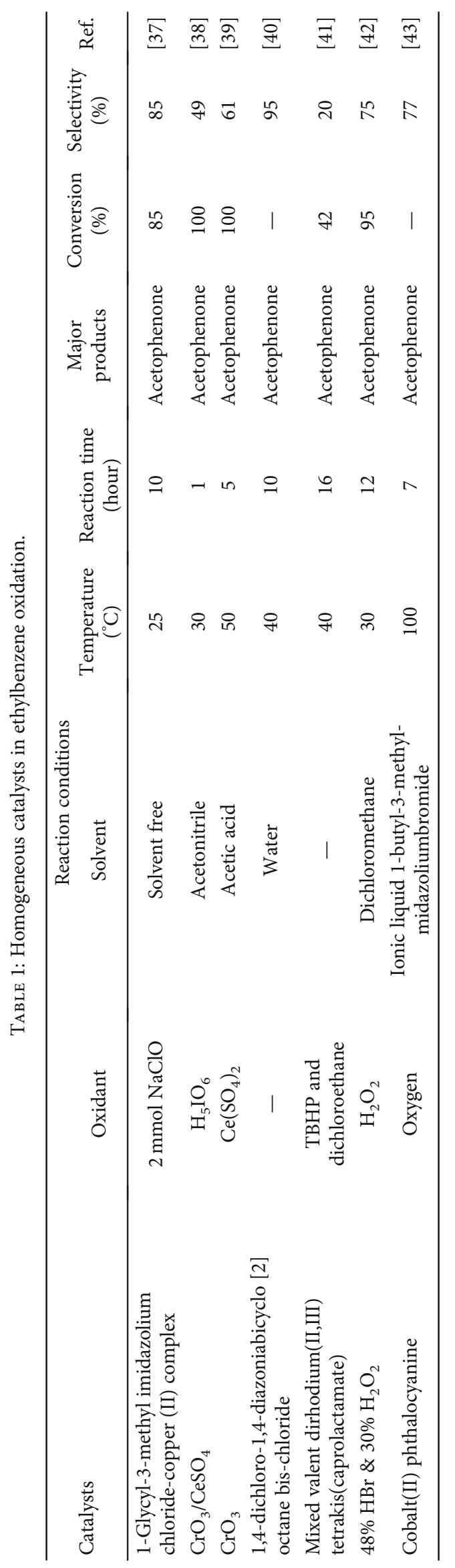




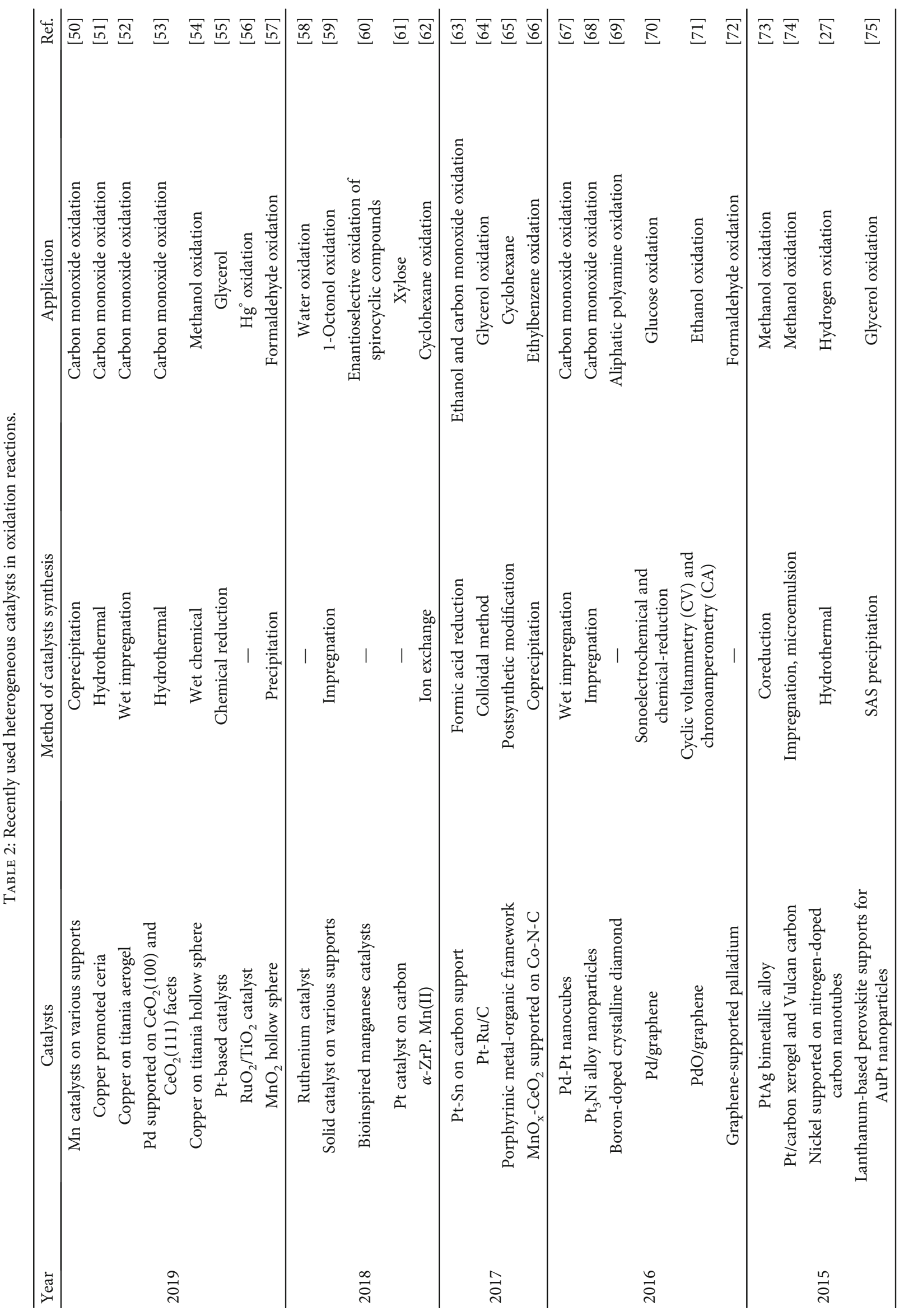




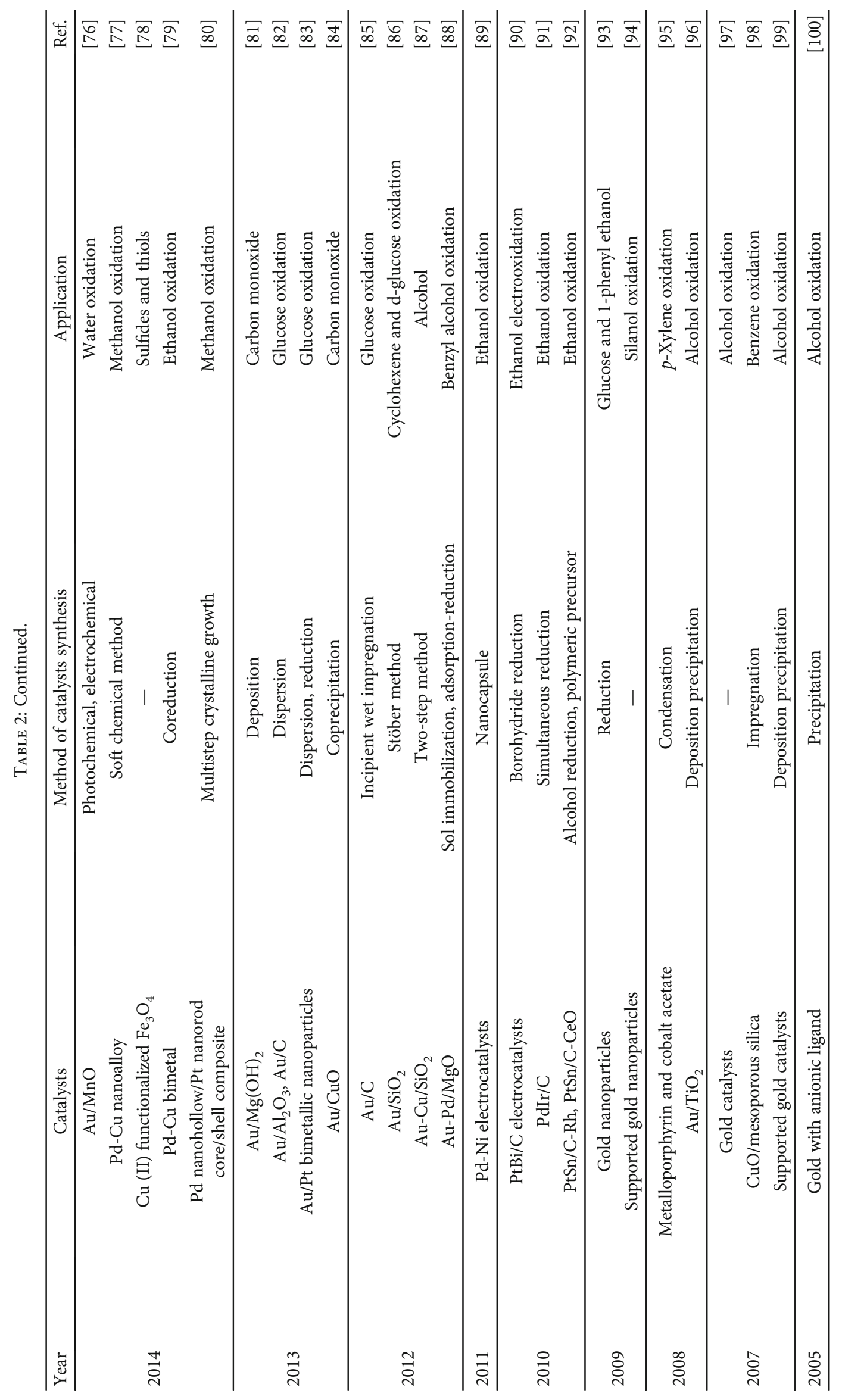




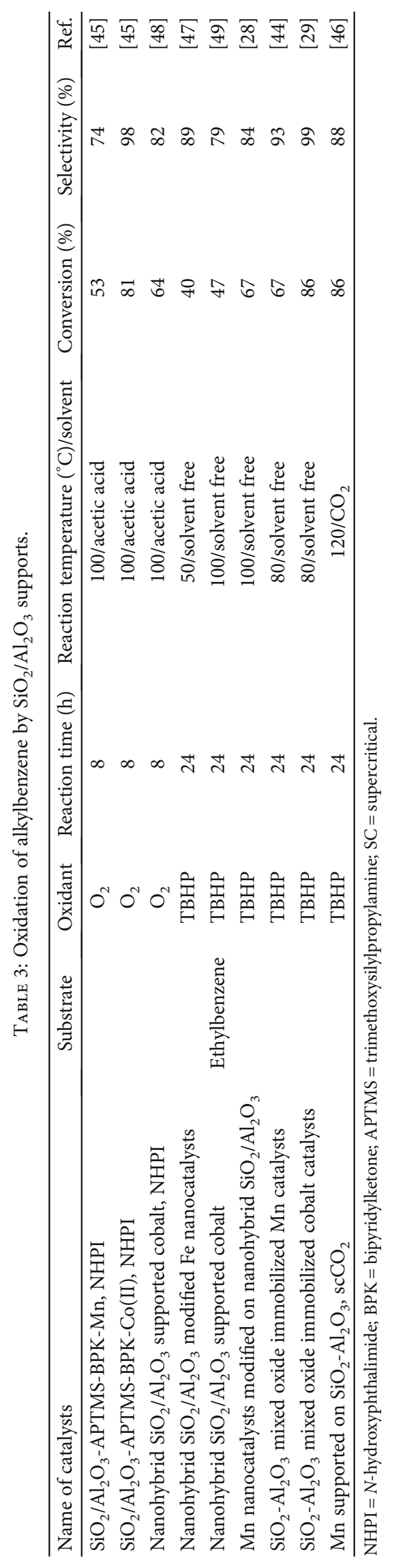




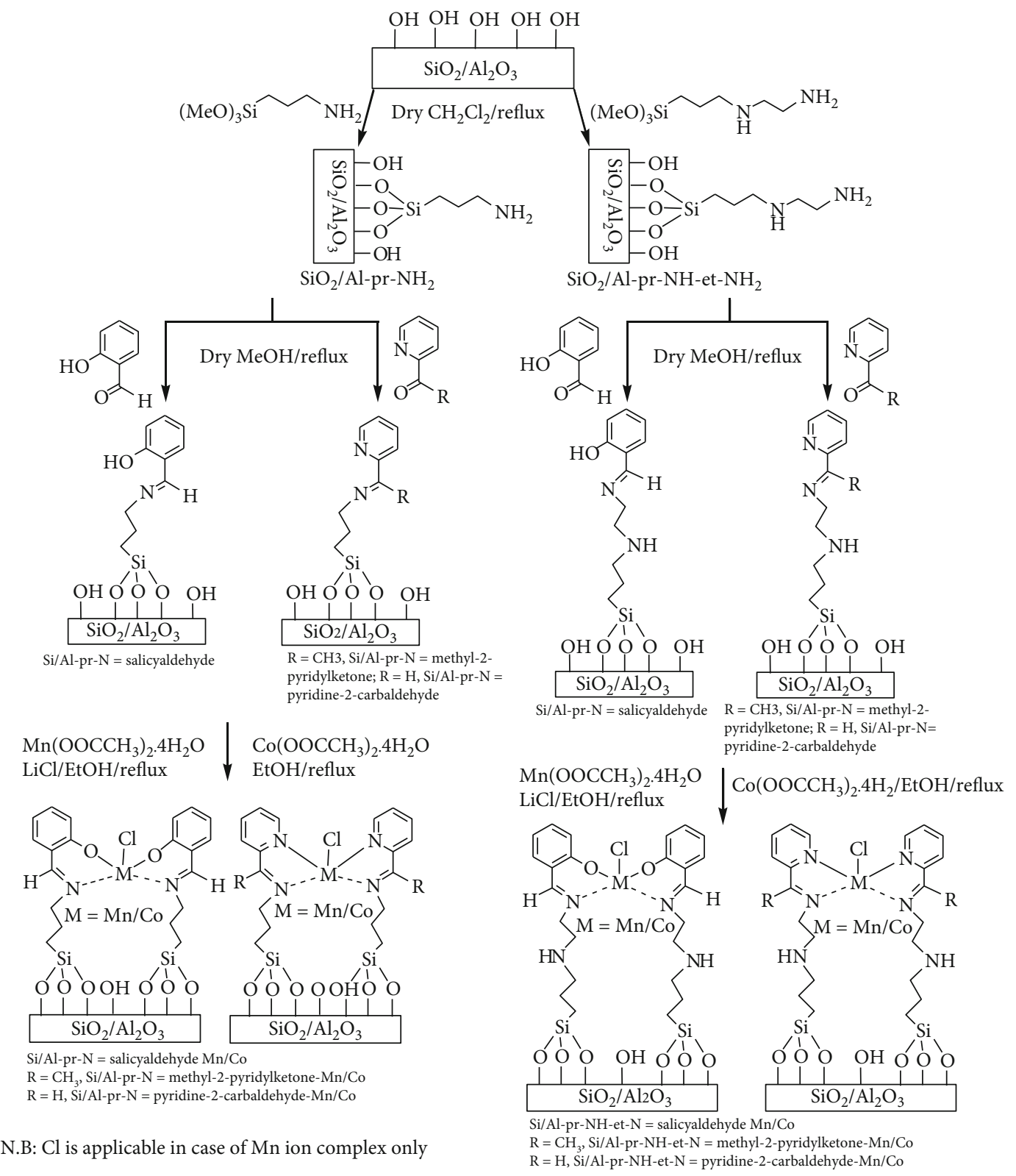

Figure 2: Immobilization of metal $(\mathrm{Mn} / \mathrm{Co})$ ion onto functionalized $\mathrm{SiO}_{2} / \mathrm{Al}_{2} \mathrm{O}_{3}$ using linker molecule. Adapted with permission from Elsevier $[29,44]$.

nanoparticles and facilitate the transport of molecules, ions, or electrons through the nanopores/nanochannels, enhancing product yields with minimum cost and time. Mal and Ramaswamy [25] reported the synthesis and catalytic activity of three different metals ( $\mathrm{Ti}, \mathrm{V}$, or $\mathrm{Sn}$ ) on silica supports (a new hydrophobic crystalline silica molecular sieve) using hydrogen peroxide as an oxidant at $60-80^{\circ} \mathrm{C}$ [101]. Of the three metallosilicates, $\mathrm{Sn}$-silicalite-I was very reactive with $\mathrm{H}_{2} \mathrm{O}_{2}$, accounting for $60 \%$ catalytic efficiency. On the other hand, TS-1 (Si/Ti) and VS-1 (Si/V) demonstrated only $36.2 \%$ and $20.10 \%$ conversion, respectively. These catalysts oxidize ethylbenzene in two different ways: first, by hydroxylating of arene at para-position and some extending to orthoposition and, second, by adding oxygen at the side chain of primary and secondary ( $\alpha$ - and $\beta$-) carbon atom; the corre- sponding carbinols (primary/secondary), which result from the side chain oxidation, further undergo to yield aldehyde or ketone. Normally, the oxidation at $\beta$-carbon dominates over the $\alpha$-carbon. In case of TS-1, the oxidation does not occur at $\alpha$-carbon. On the other hand, both positions are oxidized by VS-1 and Sn-silicalite-1. These hydroxylation reactions proceed an ionic mechanism onto TS- 1 and TS-2 surfaces [102, 103]. Nonetheless, the product distribution reveals that the side chain product is almost 4 to 5 times higher than that of aromatic ring oxidation. Ghiaci et al. [104] immobilized $\mathrm{Mn}(\mathrm{III})$ porphyrin complexes [Mn(TMCPP)][TMCPP:5,10,15,20-tetrakis-(4-methoxycarbonylphenyl)-porphyrin] onto organo-functionalized silica gel (Figure 5). This catalyst results in $40.8 \%$ conversion but $96.6 \%$ selectivity in the liquid phase oxidation of 


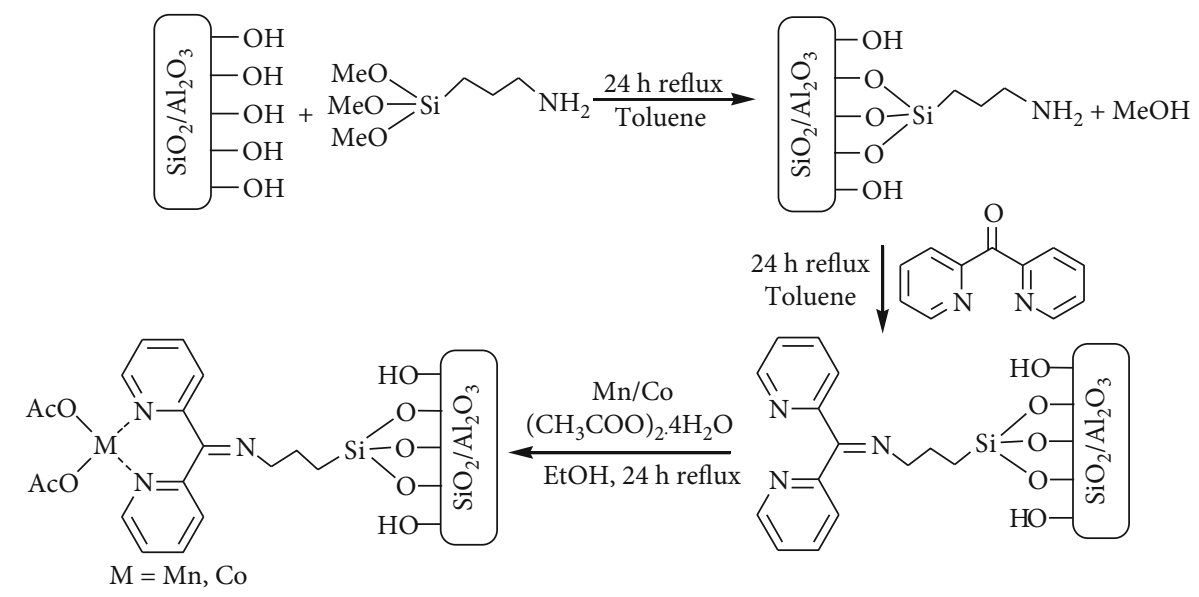

FIgURe 3: Synthetic process of Si/Al-APTMS-BPK-Mn/Co catalyst. Adapted with permission from Elsevier [28, 48].
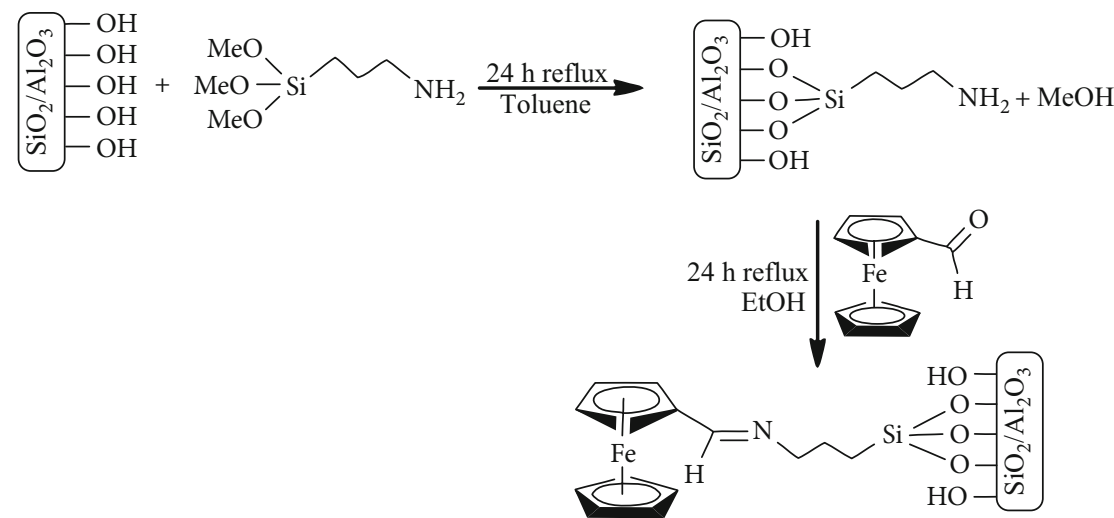

Figure 4: Immobilization of Fe on nanohybrid $\mathrm{SiO}_{2} / \mathrm{Al}_{2} \mathrm{O}_{3}$. Adapted with permission from Elsevier [47].

ethylbenzene using TBPH as oxidant and without any solvent at $150^{\circ} \mathrm{C}$. They further tested the effect of reaction time and found the catalysts exhibit maximum activity in 24 hours.

On the other hand, Rajabi and his colleagues [105] successfully prepared and employed silica supported Cobalt(II) salen complex (Figure 6); cobalt acetate was used as a source of Cobalt(II) ion, for the aerobic oxidation of ethylbenzene in presence NHPI at atmospheric pressure. The catalysts were recycled for at least four times, and in the first cycle, 78\% product yield and $91 \%$ selectivity were realized.

Biradar and Asefa [23] have stated the preparation method of gold nanoparticles as efficient catalysts for alkylbenzene oxidation by reducing $\mathrm{Au}(\mathrm{III})$ ions onto mesoporous silica functionalized by hemiaminal reducing agents (Figure 7). The supported nanoporous gold demonstrated efficient catalytic action for the oxidation of diverse range alkyl benzenes as well as linear alkanes in the presence of a TBHP oxidant. It provided unprecedented conversion ( $\sim 99 \%)$ and selectivity $(\sim 100 \%)$ toward carbonyl ketones under mild conditions. They also found that the mesoporous silica supported gold nanocatalysts exhibit the highest activity for ethylbenzene oxidation in acetonitrile followed by THF, ethyl acetate, and toluene, showing that the polar solvents have positive impact on polarity and/or dielectric con- stant of the reaction intermediates. Moreover, certain solvents outperform others by undergoing a cooxidation process which results in a more powerful oxidizing agent in the course of the reaction.

Anand et al. [26] synthesized four different types of crystalline Ag nanoparticles by impregnating silica with aqueous silver nitrate (Figure 7) and subsequent evaporation at $100^{\circ} \mathrm{C}$. The crystalline Ag nanoparticles of size $37 \mathrm{~nm}$ showed maximum conversion (92\%) and selectivity (99\%) towards acetophenone in the absence of any solvent at $90^{\circ} \mathrm{C}$. Cobalt(II) Schiff base complexes with modified silica were prepared by refluxing silica gel with 3-aminopropyl-trimethoxysilane in dry dichloromethane wherein the silica was liganded with $\mathrm{Co}\left(\mathrm{CH}_{3} \mathrm{COO}\right)_{2} \cdot 4 \mathrm{H}_{2} \mathrm{O}$ [106]. The catalysts exhibited $98 \%$ conversion and $99 \%$ selectivity towards ketone products in the presence of NHPI under an $\mathrm{O}_{2}$ atmosphere. Neeli et al. [24] prepared $\mathrm{Cu} / \mathrm{SBA}-15$ catalysts by loading $\mathrm{Cu}$ via impregnation wherein $\mathrm{Cu}\left(\mathrm{NO}_{3}\right)_{2} \cdot 3 \mathrm{H}_{2} \mathrm{O}$ is the metal source (Figure 7). At $10 \% \mathrm{Cu}$ loading, the maximum conversion (94\%) and selectivity (99\%) to acetophenone under solventfree condition were achieved at $90^{\circ} \mathrm{C}$.

In another instance, Dan-Hua et al. [36] immobilized manganese porphyrin onto silica nanoparticles on $\mathrm{Fe}_{3} \mathrm{O}_{4}$ solid matrixes. The catalysts become active upon the removal of the hard template of the silica supports. 
$-\mathrm{OH}$
$-\mathrm{OH}$
$-\mathrm{OH}$

Surface silanol group of silica

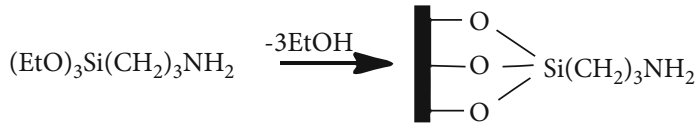

3-Aminopropyltriethoxysilane (APTS)
SF-3-APTS

NaH, TMCPP, THF, reflux, $72 \mathrm{~h} \mathrm{~N}_{2}, \mathrm{MnCl}_{2} 4 \mathrm{H}_{2} \mathrm{O}, \mathrm{DMF}$,

$\checkmark$ $140^{\circ} \mathrm{C}, 4 \mathrm{~h}, \mathrm{~N}_{2}$

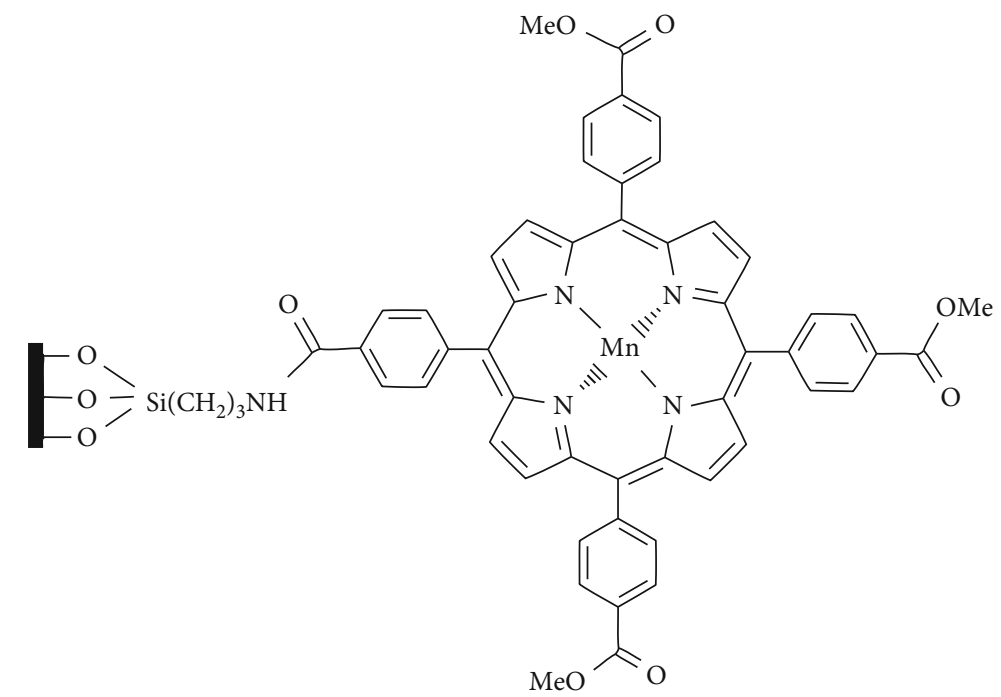

Mn porphyrin complex

FIGURE 5: Metalloporphyrin metal ion covalently bound to silica. Adapted with permission from Elsevier [104].

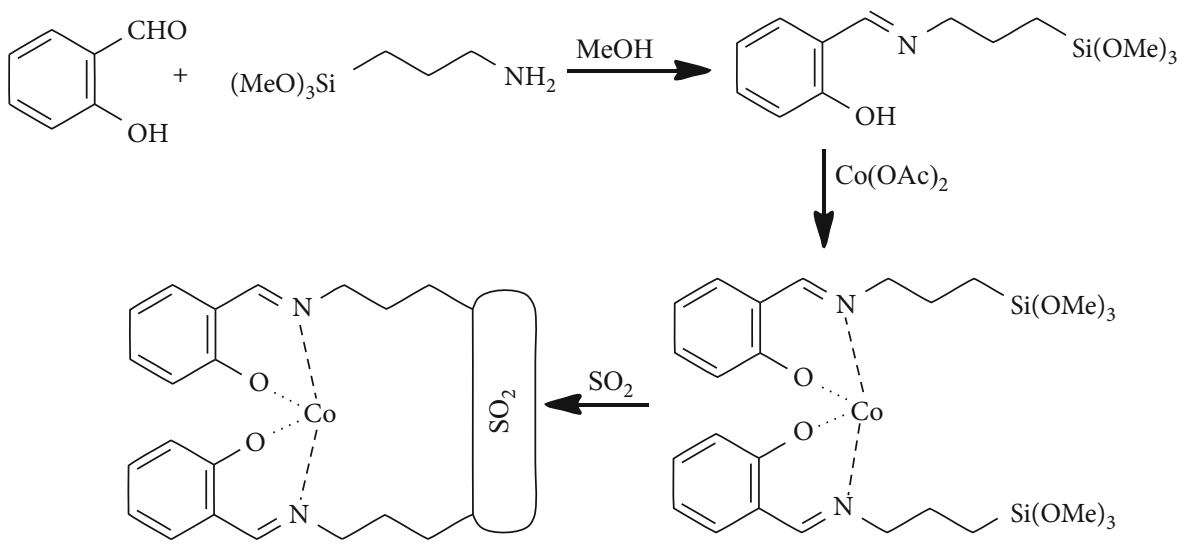

Figure 6: Preparation of silica supported Cobalt(II) catalyst. Adapted with permission from Elsevier [105].

Metalloporphyrin was fixed onto the inner surface of hollow microspheres allowing a substrate to diffuse onto grafted manganese porphyrin through the pore of the silica shell. The catalysts were recycled for six times with the retention of high activity and stability. Bhoware et al. [107] prepared cobalt nanocatalysts onto hexagonal mesoporous materials (Co-HMS and Co/HMS) by grafting various cobalt contents via hydrothermal and postsynthesis methods. The catalysts exhibited good activity for liquidphase ethylbenzene oxidation in the presence of the TBHP oxidant wherein $\mathrm{H}_{2} \mathrm{O}_{2}$ was inactive under solvent-free condition accounting for $49.5 \%$ and $39.0 \%$ by Co-HMS and $\mathrm{Co} / \mathrm{HMS}$, respectively, in a 24 -hour reaction at $80^{\circ} \mathrm{C}$; Co/HMS catalysts exhibited greater selectivity (59\%) towards acetophenone. Sujandi et al. [108] immobilized $\mathrm{Co}$ (III) ion onto cyclam (macrocyclic ring, Scheme 2) complexed to functionalized SBA-15 with a chloropropyl group through surface substitution reaction. This cyclam group deposits Cobalt(II) into its cavity that facilitates ethylbenzene oxidation with better conversion efficiency 


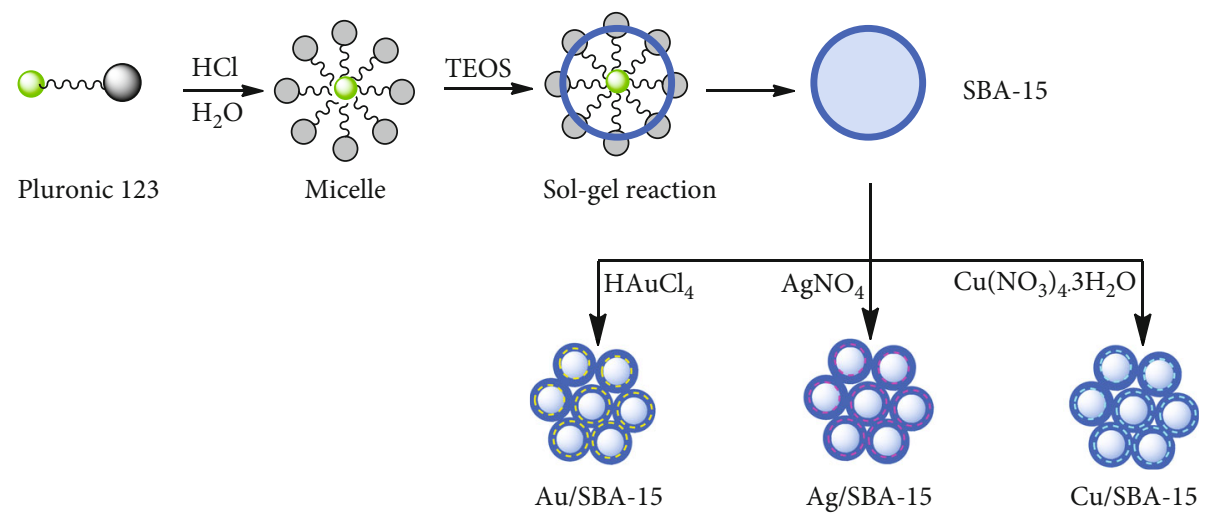

FIGURE 7: General procedure for the synthesis of silica-supported metal catalysts.

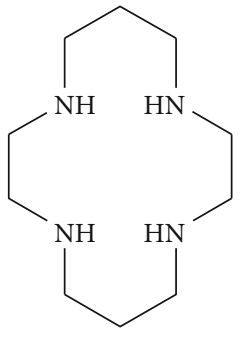

Cyclam ring

SCHEMe 2

(60\%). The presence of a pyridine group to the axial site of $\mathrm{Co}$ (III) cyclam composite was further investigated, conferring that this group enhances the ethylbenzene conversion by $10 \%$ without losing the selectivity towards acetophenone. Major silica-based catalysts for ethylbenzene oxidation are summarized in Table 4.

3.2.3. Miscellaneous. Apart from these, a good number of catalysts are being used for ethylbenzene oxidation (Table 5). Rebelo et al. [110] synthesized and studied the activity of five different types of $\mathrm{Mn}$ (III) porphyrin complexes in ammonium acetate as cocatalysts. Among these, $\mathrm{Mn}\left(\beta-\mathrm{NO}_{2} \mathrm{TDCPP}\right) \mathrm{Cl}$ provided the highest conversion and selectivity due to the presence of a nitro group. The cocatalysts for hydrogen peroxide activation included the buffering substances, i.e., ammonium acetate [111], imidazole [112], and pyridine plus benzoic acid [113]. However, the evidence of pyridine oxidation was also observed [114]. Xavier et al. [115] reported Y-zeolite supported $\mathrm{Co}(\mathrm{II})$, $\mathrm{Ni}(\mathrm{II})$, and $\mathrm{Cu}(\mathrm{II})$ centers of dimethylglyoxime and $N, N^{\prime}$ -ethylenebis (7-methylsalicylideneamine) which were prepared in situ by reaction of ion-exchanged metal ions with disulfide flexible ligands. However, $\mathrm{Cu}$ (II)-zeolite complexes demonstrated maximum efficiency wherein the reactivity of the complex is believed to be provided by the geometry of encapsulated molecules as well as the steric condition of active sites. The supported zeolite composites are highly stationary to be recycled and are apt to be used as catalysts for partial oxidation. Choudhary et al. [116] investigated the cat- alytic effect of $\mathrm{MnO}_{4}{ }^{-1}$-exchanged $\mathrm{Mg}$-Al hydrotalcite which is a stable and green catalyst for the oxidation of a methylene group, covalently attached to an aromatic ring under an oxygen atmosphere. They found that the activity of methyleneto-carbonyl conversion by $\mathrm{MnO}_{4}^{-1}$-exchanged hydrotalcite, the decomposition of $\mathrm{H}_{2} \mathrm{O}_{2}$, and the basicity of $\mathrm{Mg}$ - $\mathrm{Al}$ hydrotalcite rises with the raising $\mathrm{Mg} / \mathrm{Al}$ ratio in the catalyst and the $\mathrm{Mg} / \mathrm{Al}$ ratio at 10 ; the highest catalytic activity as well as selectivity (above 95\%) was obtained for ethylbenzene oxidation to acetophenone and diphenylmethane to benzophenone. These reactions were fully heterogeneous, but no leaching of the active component(s) from the catalyst was observed. The recycled catalyst exhibited good performance after its first use in the oxidation reaction.

Bennur et al. [117] synthesized copper tri- and tetraaza macrocyclic complexes by encapsulating Y-type zeolite. The "neat" and encapsulated complexes showed noble performance in ethylbenzene oxidation at $60^{\circ} \mathrm{C}$ using TBHP as an oxidant. While the encapsulated complexes showed enhanced selectivity towards acetophenone, a small quantity of $o^{-}$and $p$-hydroxyacetophenones was also yielded, reflecting that $\mathrm{C}-\mathrm{H}$ bond activation takes place both at benzylic and at aromatic ring carbon atoms. It is inferred that ring hydroxylation takes place more over the "neat" complexes than over the encapsulated complexes. This difference is due to the formation of various types of "active" copper-oxygen intermediates, such as bis- $\mu$-oxo complexes and $\mathrm{Cu}$-hydroperoxo species, at different proportions over the "neat" and encapsulated complexes. In 2006, Jana et al. [118] prepared different $\mathrm{NiAl}$ hydrotalcites by a conventional precipitation technique using $\mathrm{Ni} / \mathrm{Al}$ at molar ratios of 2-5 in guest inorganic anions such as $\mathrm{CO}_{3}{ }^{2-}$ and $\mathrm{Cl}^{-}$; these carried out the liquid-phase oxidation of the methylene group of ethyl-substituted benzene to acetophenone under an atmospheric oxygen as the sole oxidant in a solvent-free system at $135^{\circ} \mathrm{C}$. In the presence of $\mathrm{CO}_{3}{ }^{2-}$ anion and $\mathrm{Ni} / \mathrm{Al}$ ratio $5 \mathrm{~mol} \mathrm{~mol}^{-1}$, it showed higher activity for ethylbenzene oxidation with $99 \%$ selectivity towards acetophenone than those prepared using $\mathrm{Cl}^{-}, \mathrm{NO}_{3}{ }^{-}$, or $\mathrm{SO}_{4}{ }^{2-}$ anions. Other hydrotalcite congaing transition-metal solid catalysts such as $\mathrm{CuAl}-, \mathrm{ZnAl}-$, CoAl-, $\mathrm{MgFe}-$, and $\mathrm{MgCr}$ - demonstrated higher activity than that of NiAl hydrotalcite. However, the active NiAl hydrotalcite presented 
TABLE 4: Oxidation of alkylbenzene by $\mathrm{SiO}_{2}$ supports.

\begin{tabular}{|c|c|c|c|c|c|c|c|}
\hline Name of catalysts & Substrate & Oxidant & $\begin{array}{l}\text { Reaction } \\
\text { time }(\mathrm{h})\end{array}$ & $\begin{array}{l}\text { Reaction temperature } \\
\left({ }^{\circ} \mathrm{C}\right) / \text { solvent }\end{array}$ & $\begin{array}{c}\text { Conversion } \\
(\%)\end{array}$ & $\begin{array}{l}\text { Selectivity } \\
\text { (\%) }\end{array}$ & Ref. \\
\hline $\begin{array}{l}\text { Ti, V \& Sn containing silicalite } \\
\text { molecular sieves }\end{array}$ & & $\mathrm{H}_{2} \mathrm{O}_{2}$ & 24 & $\begin{array}{l}\text { 80/tert-butanol, acetone, } \\
\text { water }\end{array}$ & - & - & {$[25]$} \\
\hline Silica gel supported cobalt, NHPI & & $\mathrm{O}_{2}$ & 24 & 100/acetic acid & 98 & 99 & [106] \\
\hline $\mathrm{Cu} / \mathrm{SBA}-15$ & & ТВНP & 5 & $90 /$ solvent free & 94 & 99 & {$[24]$} \\
\hline Metalloporphyrin@SiO 2 & Ethylbenzene & $\mathrm{O}_{2}$ & - & $100 /$ solvent free & 16 & 74 & {$[36]$} \\
\hline Ag/SBA-15 & & ТВНP & 5 & $90 /$ solvent free & 92 & 99 & {$[26]$} \\
\hline $\mathrm{Au} / \mathrm{SBA}-15$ & & ТВHP & 36 & 70/acetonitrile & 79 & 93 & {$[23]$} \\
\hline Silica supported cobalt, NHPI & & $\mathrm{O}_{2}$ & $<12$ & 100/acetic acid & 78 & 91 & [105] \\
\hline SF-ATPS-Mn(III)TMCPP & & ТВНP & 24 & $150 /$ solvent free & 40 & 96 & {$[104]$} \\
\hline CO/HMS & & ТВHP & 24 & $80 /$ solvent free & 49 & 60 & [107] \\
\hline $\begin{array}{l}\text { Co (III) cyclam functionalized } \\
\text { mesoporous silica }\end{array}$ & & Air flow & 8 & -/acetonitrile & 20 & 60 & [108] \\
\hline $\begin{array}{l}\text { Mn-metformin complex on } \\
\text { modified } \\
\text { magnetic } \mathrm{SiO}_{2} @ \mathrm{Fe}_{3} \mathrm{O}_{4} \text { core/shell }\end{array}$ & & $\mathrm{O}_{2}$ & 8 & 100/acetic acid & 85 & 98 & [109] \\
\hline
\end{tabular}

TMCPP: 5,10,15,20-tetrakis(4-methoxy carbonyl phenyl) porphyrin; AMTS = aminopropyl-trimethoxysilane.

TABLE 5: Oxidation of ethylbenzene with various catalytic supports materials.

\begin{tabular}{|c|c|c|c|c|c|c|c|}
\hline Name of catalysts & Substrate & Oxidant & $\begin{array}{l}\text { Reaction } \\
\text { time }(\mathrm{h})\end{array}$ & $\begin{array}{c}\text { Reaction temperature } \\
\left({ }^{\circ} \mathrm{C}\right) / \text { solvent }\end{array}$ & $\begin{array}{c}\text { Conversion } \\
(\%)\end{array}$ & $\begin{array}{l}\text { Selectivity } \\
(\%)\end{array}$ & Ref. \\
\hline $\begin{array}{l}\text { Manganese (III) porphyrin, } \\
\text { ammonium acetate }\end{array}$ & \multirow{23}{*}{ Ethylbenzene } & & 5.5 & $\begin{array}{c}\text { Room } \\
\text { temperature/acetonitrile }\end{array}$ & 66 & 66 & [110] \\
\hline Zeolite-encapsulated Cu (II) & & $\mathrm{H}_{2} \mathrm{O}_{2}$ & 8 & 70/benzene & 46 & 66 & [115] \\
\hline MnO 4-1 exchanged Mg-Al hydrotalcite & & $\mathrm{O}_{2}$ & 5 & -/solvent free & 22 & 98 & [116] \\
\hline $\mathrm{Cu}(\operatorname{tacn})\left(\mathrm{ClO}_{4}\right)_{2}$ & & ТВНР & 10 & 60/acetonitrile & 49 & 91 & [117] \\
\hline $\mathrm{Ni} / \mathrm{Al}$ hydrotalcites, $\mathrm{CO}_{3}{ }^{2-}$ & & $\mathrm{O}_{2}$ & 5 & $135 /$ solvent free & 47 & 99 & [118] \\
\hline Vanadia/ceria & & $\mathrm{H}_{2} \mathrm{O}_{2}$ & 6 & 60/acetonitrile & 20 & 72 & [119] \\
\hline $\begin{array}{l}\text { Cobalt(II)(5,10,15,20-tetrakis } \\
\text { (pentafluorophenyl))porphyrin }\end{array}$ & & $\mathrm{O}_{2}$ & 24 & $100 /$ solvent free & 38 & 94 & {$[120]$} \\
\hline Hemin/NHPI & & $\mathrm{O}_{2}$ & 9 & 100/acetonitrile & 92 & 94 & [121] \\
\hline Supported nickel & & $\mathrm{O}_{2}$ & 5 & $150 /$ solvent free & 20 & 80 & [122] \\
\hline Metal-doped $\mathrm{HS}-\mathrm{ALF}_{3}$ & & ТВНP & 6 & 60/acetonitrile & 70 & 72 & [125] \\
\hline Macrocyclic copper (II) complex & & ТВНР & 10 & 60/acetonitrile & 62 & 88 & [126] \\
\hline DAEP-bentonite-Pd (II) & & ТВНP & 24 & $80 /$ solvent free & 92 & 93 & [127] \\
\hline Ni substituted copper chromite spinel & & ТВНP & 8 & 70/acetonitrile & 56 & 68 & [128] \\
\hline Vanadium complex/NHPI system & & $\mathrm{O}_{2}$ & 12 & 90/Benzonitrile & 69 & 97 & [142] \\
\hline Mesoporous $\mathrm{Cu}-\mathrm{ZrPO}$ & & ТНВР & 24 & 80/Benzonitrile & 91 & 87 & [145] \\
\hline $\begin{array}{l}\text { Immobilized bidentate Schiff base } \\
\text { oxovanadium(IV) complex }\end{array}$ & & $\mathrm{O}_{2}$ & 14 & $110 /$ solvent free & $\sim 40$ & 98 & [143] \\
\hline Fe@CNT & & $\mathrm{O}_{2}$ & 3 & 155/acetonitrile & 36 & 60 & [144] \\
\hline Supported $\mathrm{Co}_{4} \mathrm{HP}_{2} \mathrm{Mo}_{15} \mathrm{~V}_{3} \mathrm{O}_{62}$ & & $\mathrm{H}_{2} \mathrm{O}_{2}$ & - & 70/glacial acetic acid & 72 & 95 & {$[146]$} \\
\hline$\mu$-Oxo dimeric metalloporphyrins & & $\mathrm{O}_{2}$ & 2 & $65 /$ solvent free & 91 & 99 & {$[147]$} \\
\hline $\begin{array}{l}\text { Cobalt-supported catalysts on } \\
\text { modified MNPs }\end{array}$ & & $\mathrm{O}_{2}$ & 10 & 100/ethanol & 88 & 98 & [148] \\
\hline Carbon nanotube & & $\mathrm{O}_{2}$ & 4 & 155/acetonitrile & 40 & 62 & [149] \\
\hline $\mathrm{Mn} / \mathrm{N}-\mathrm{C} / \mathrm{Al}_{2} \mathrm{O}_{3}$ & & $\mathrm{O}_{2}$ & 6 & $120 /$ solvent free & 27 & 99 & {$[150]$} \\
\hline $\begin{array}{l}\text { Mesosubstituted pyrazolyl } \\
\text { porphyrin complexes }\end{array}$ & & ТВНP & & $80 /$ water & 99 & 99 & [151] \\
\hline
\end{tabular}

Tacn = triazacyclononane; HMS = hexagonal mesoporous materials; MNPs = magnetic nanoparticles. 
better performance in the oxidation of a variety of alkylaromatics to their corresponding benzylic ketones under similar reaction conditions. Additionally, the preparation of $\mathrm{NiAl}$ hydrotalcite is very cheap and stable using commercially available reagents.

Radhika and Sugunan [119] impregnated ammonium metavanadate in oxalic acid solution to prepare vanadia/ceria catalysts $\left(2-10 \%\right.$ of $\left.\mathrm{V}_{2} \mathrm{O}_{5}\right)$ and carried out liquid-phase oxidation of ethylbenzene with $\mathrm{H}_{2} \mathrm{O}_{2}$. It was found that the activity was increased with loading of $\mathrm{V}_{2} \mathrm{O}_{5}$ up to $8 \%$; however, it decreased after $\mathrm{V}_{2} \mathrm{O}_{5}$ content (10\%). In some instances, catalytic activity increases even after vanadia loading beyond 10\%, but selectivity towards acetophenone decreases. Product analysis indicated that when vanadia loading higher than $6 \%$, it oxidizes the acetophenone to 2hydroxyacetophenone. XRD and FT-IR analysis revealed the existence of extremely dispersed vanadia at lower loading, but formation of $\mathrm{CeVO}_{4}$ when vanadia loading exceeded to $10 \% \mathrm{~V}_{2} \mathrm{O}_{5}$. Vanadia exhibits tetrahedral properties at lower loading, but it forms $\mathrm{Ce}-\mathrm{O}-\mathrm{V}$ species onto the support surface; this exhibited the existence of highly dispersed tetrahedral species at lower loading but agglomeration at the higher extremes. Benzaldehyde production predominates with $\mathrm{Ce}-\mathrm{O}-\mathrm{Ce}$ but acetophenone is the major product with $\mathrm{V}-\mathrm{O}-\mathrm{V}$ structure.

Li et al. [120] described the oxidation process of ethylbenzene with fluorinated metalloporphyrins under a normal environment without any additives. They synthesized three different types of [5,10,15,20-tetrakis(pentafluorophenyl)] porphyrin with $\mathrm{Fe}, \mathrm{Mn}$, and $\mathrm{Co}$ at the centers, and Co(II) (5,10,15,20-tetrakis(pentafluorophenyl))porphyrin was found to be the ideal metalloporphyrins; these exhibited $38.6 \%$ conversion for ethylbenzene $94 \%$ selectivity towards acetophenone along with 2719 turnover numbers under optimal conditions (at $100^{\circ} \mathrm{C}$ and $24 \mathrm{~h}$ ). Ma et al. [121] investigated the selective oxidation of ethyl substituted benzene with iron-containing hemin (a biomimetic system of catalysts) with molecular oxygen in acetonitrile. They reported $90.32 \%$ conversion of ethylbenzene and $94.30 \%$ selectivity toward acetophenone at $100^{\circ} \mathrm{C}$ under $0.3 \mathrm{MPa} \mathrm{O} 2$ for $9 \mathrm{~h}$. In situ formed 1-phenylethyl hydroperoxide (PEHP) can easily be decomposed via a hemolytic cleavage by Hemin complex to acetophenone.

Raju et al. [122] studied the aerobic oxidation of ethylbenzene without any solvent or any other additives using nickel on various supports such as $\mathrm{SiO} 2$, hydroxyapatite, SBA-15, and USY zeolites prepared by impregnation. Hydroxyapatite- and USY- (13\% Na2O) supported nickel catalysts showed better conversion and selectivity toward acetophenone due to the presence of a proper amount of comparatively weak acid sites which accelerate the formation of a major product [123], whereas the strong acid sites fasten the formation of side products [124]. Accordingly, the sample having a greater number of intermediate strength acidic points presented high conversion with reasonable selectivity to acetophenone in comparison to samples having a greater number of strong acidic points. It is also identified that additional acidic catalysts usually favor the breaking of hydrocarbons, thereby expediting the formation of more undesirable by-products and coke that lead to the deactivation of catalysts.

In 2008, Murwani et al. [125] synthesized pure and doped high surface aluminum fluorides (HS-AlF3) with various reactive metals like iron $(\mathrm{Fe})$, vanadium $(\mathrm{V})$, manganese $(\mathrm{Mn})$, and niobium $(\mathrm{Nb})$ by means of sol-gel fluorination. Of the four different types of reactive metals, $\mathrm{V}$ and $\mathrm{Fe}$ doped aluminum fluoride produced the best results in ethylbenzene conversion and selectivity towards acetophenone at $60^{\circ} \mathrm{C}$ and solvent to TBHP ratio $1: 3$ since these two metals are rich with surface Lewis acid sites having abundant chemisorption capability to oxygen. It was also found that acetonitrile is the standard solvent. Mn-doped sample contained little quantity of medium-weak Lewis acid sites; however, $\mathrm{Nb}$-doped aluminum fluoride exhibited very high concentration of Bronsted acid sites, on the educts that could not be necessarily activated. The functions of acid sites include (a) the activation of the tert-butyl hydroperoxide on doped metal fluorides acting as Lewis acid and redox center and (b) the yielding of acetophenone from ethylbenzene as a major product. Unfortunately, vanadium ion containing HS-AlF3 which has a leaching effect did not show ethylbenzene conversion under reaction condition.

Salavati-Niasari [126] encapsulated copper(II) complexed with twelve-membered cyclic ligands containing three contributing atoms $\left(\mathrm{N}_{2} \mathrm{O}_{2}, \mathrm{~N}_{2} \mathrm{~S}_{2}\right.$, and $\left.\mathrm{N}_{4}\right)$ in macrocyclic ring in zeolite-Y nanocavity with a flexible ligand method in a two-step liquid phase reaction. This, first, adsorbs the ligand source, 1,2-di(o-aminophenyl-, amino, oxo, thio)ethane, $\mathrm{N}_{2} \mathrm{X}_{2}$ in the supercages of the $\mathrm{Cu}(\mathrm{II})-\mathrm{NaY}$ and, finally, condenses the $\mathrm{Cu}(\mathrm{II})$ precursor complex $\left[\mathrm{Cu}\left(\mathrm{N}_{2} \mathrm{X}_{2}\right)\right]^{2+}$ with glyoxal or biacetyl. Good catalytic action (58.2\%) with high selectivity was found in ethylbenzene oxidation by zeolite encapsulated ligand complexes at $60^{\circ} \mathrm{C}$ using TBHP oxidant; this is because the encapsulated complexes ensure uniform dispersion of metal complexes inside the nanoporous support which gives the structural integrity. The zeolite structure can retain the visitor multiplexes dispersed and inhibit their dimerization.

In 2010, Ghiaci et al. [127] synthesized the palladium nanotubes as well as nanoparticles onto bentonite (an absorbent) modified with 3,3-(dodecylazanediyl)-bis-( $N$-(2-(2aminoethylamino)-ethyl)propanamide) (DAEP) having an aliphatic tail (C-12) and a hydrophilic head. This modified bentonite, called DAEP-bentonite, was operated as a nanoreactor for the synthesis of $\mathrm{Pd}^{2+}$ and $\mathrm{Pd}^{0}$ nanoparticles. They carried out oxidation of ethylbenzene and found that $\mathrm{Pd}^{2+}$ on functionalized bentonite along with cetylpyridinium bromide and DAEP showed higher activity compared to $\operatorname{Pd}(0)$ onto identical support materials under similar reaction condition.

George and Sugunan [128] synthesized five different types of spinels, namely, CCr, CNCr-1, CNCr-2, CNCr-3, and $\mathrm{NCr}$ depending on $\mathrm{Cu}, \mathrm{Ni}$, and $\mathrm{Cr}$ by a coprecipitation method with the use of three consecutive nitrates such as copper nitrate, nickel nitrate, and chromium nitrate. In the liquid-phase oxidation of ethylbenzene, $\mathrm{CNCr}-2$ resulted in the maximum conversion (56.1\%) and selectivity $(68.7 \%)$ under the same reaction condition. They also tested the 
TABLE 6: Activity of graphitic nitrogen materials in selective oxidation of ethylbenzene [152].

\begin{tabular}{lccccc}
\hline Entry & Sample & Acetophenone (\%) & Nitrogen element (\%) & Oxygen element (\%) & Graphitic nitrogen (\%) \\
\hline 1 & Ac-250 & 55.9 & 0.59 & 11 & 0.21 \\
2 & Ac-450 & 84.1 & 4.8 & 7.9 & 1.2 \\
3 & Ac-650 & 87.9 & 3.8 & 3.0 & 1.4 \\
4 & Ac-850 & 81.6 & 6.1 & 3.0 & 3.4 \\
$5^{*}$ & Ac-850 & 49.9 & 6.1 & 9.5 & 0.18 \\
6 & Am-250 & 55.8 & 2.0 & 7.9 & 0.35 \\
7 & Am-450 & 86.5 & 2.6 & 3.9 & 0.77 \\
8 & Am-650 & 93.2 & 4.6 & 4.6 & 1.1 \\
9 & Am-850 & 57.9 & 5.2 & 4.6 & 1.1 \\
$10^{*}$ & Am-850 & 81.9 & 5.2 & & \\
\hline
\end{tabular}

Reaction conditions: $1 \mathrm{mmol}$ ethylbenzene, $3 \mathrm{mmol}$ TBHP, $10 \mathrm{mg}$ catalyst, and $3 \mathrm{~mL} \mathrm{H} \mathrm{H}_{2} \mathrm{O}$ were put into a $50 \mathrm{~mL}$ sealed pressure glass vessel with magnetic stirring $\left(80^{\circ} \mathrm{C}\left({ }^{*} 65^{\circ} \mathrm{C}\right)\right) 24 \mathrm{~h}$.

efficiency of various solvents on catalytic activity and found better product in the absence of a solvent. A mechanistic scheme revealed chromite would be a convenient and ecofriendly alternative for hazardous oxidants. NHPI can efficiently improve the aerobic oxidation of hydrocarbon by combining with various mediators such as metal compounds [129-132], hemin [121], oximes [133], anthraquinones [134], o-phenanthroline [135], azobisisobutyronitrile (AIBN) [136], Ce(IV) [137], alkaline-earth chlorides [138], $\mathrm{I}_{2} / \mathrm{HNO}_{3}$ [139], NO2 [140], and quaternary ammonium salts [141].

Qin et al. [142] investigated the conciliation effect of vanadium complexes on ethylbenzene oxidation using $\mathrm{N}$ hydroxyphthalimide (NHPI) at $90^{\circ} \mathrm{C}$ in benzonitrile. Of the vanadium mediators used, a sequence of oxobis (8-quinolinolato) vanadium(IV) complexes synthesized by coordination of 8-hydroxyquinoline or its derivatives with oxobis (2,4-pentanedionate) vanadium $(\mathrm{IV})\left(\mathrm{V}^{\mathrm{IV}} \mathrm{O}(\mathrm{acac})_{2}\right)$ exhibited a better mediation effect compared to $\mathrm{V}^{\mathrm{IV}} \mathrm{O}(\mathrm{acac})_{2} \cdot \mathrm{NH}_{4} \mathrm{VO}_{3}$ and $\mathrm{V}_{2} \mathrm{O}_{5}$ giving 60-69\% conversion of ethylbenzene and $97 \%$ selectivity towards ketone product under optimum reaction condition because of the dual effect of vanadium mediators on NHPI transformation to phthalimide- $N$-oxyl(PINO) radical as well as the breakdown of 1-phenylethyl hydroperoxide to acetophenone [142].

A new immobilized bidentate Schiff base oxovanadium(IV) complex was prepared [143] using chloromethylated crosslinked polystyrene microspheres (CMCPS microspheres), a starting carrier. First, the chloromethyl group of CMCPS microspheres was transferred to the aminomethyl group through Delépine reaction with a hexamethylenetetramine (HMTA) reagent forming aminomethylated (AM) microspheres (AMCPS). Secondly, the Schiff base reaction between the primary amino group of AMCPS and salicylaldehyde (SA) resulted in Schiff base-type resin microspheres (SAAM-CPS) on which bidentate Schiff base ligand SAAM were chemically attached. The subsequent coordination between the ligand SAAM of SAAM-CPS micropores and vanadyl sulfate $\left(\mathrm{VOSO}_{4}\right)$ formed heterogeneous oxovanadiu$\mathrm{m}(\mathrm{IV})$ complex catalyst, chemically immobilized bidentate Schiff base-type oxovanadium(IV) complex, and CPS-
$\mathrm{VO}(\mathrm{SAAM})_{2}$ microspheres. This complex efficiently carried out oxidation of ethylbenzene under mild conditions with excellent reusability.

Luo et al. [144] prepared an iron nanowire-filled carbon nanotube (Fe@CNT), a magnetic separable heterogeneous catalyst by chemical vapor deposition. Selective oxidation of ethylbenzene showed that iron nanowire competently improved CNTs activity by accelerating electron transfer in dioxygen. Besides, Fe@CNTs could be recycled after consecutive six cycles with no loss of its catalytic activity simply by applying external magnetic force. Miao et al. [145] synthesized a sequence of mesoporous $\mathrm{Cu}-\mathrm{ZrPO}$ (M-Cu-ZrPO) catalysts for liquid-phase ethylbenzene oxidation with a surface area of $\sim 200 \mathrm{~m}^{2} / \mathrm{g}$, uniform pore size of $\sim 7.8 \mathrm{~nm}$, and various copper content (0-30\%) by facile one-pot evaporation. They stated that $\mathrm{M}-\mathrm{Cu}-\mathrm{ZrPO}$ can retain its thermal stability, reusability (more than five cycles), and ordered mesostructure even after heating at $700^{\circ} \mathrm{C}$. Due to its stability, the activity of $\mathrm{M}-\mathrm{Cu}-\mathrm{ZrPO}$ steadily increased with raising copper contents up to $30 \%$ with conversion $91.2 \%$ and selectivity $87 \%$ towards acetophenone.

Tang et al. [152] synthesized and looked into the effect of several $\mathrm{N}$-doped graphene in ethylbenzene oxidation. In all these reactions yielded acetophenone as the major products and little amount of benzaldehyde and benzoic acid as by-products. In the $\mathrm{N}$-doped graphene catalytic system, it is not only the nitrogen but also the graphitic nitrogen catalyzes the conversion of ethylbenzene to acetophenone because the graphitic nitrogen is liable for TBHP activation [153]. However, too much N-doped graphene demonstrated an adverse effect on the activity. Usually, at high temperature, $\mathrm{N}$-doped graphene exhibited good catalytic activity in comparison to those reacted at low temperature. Tang et al. also correlated the total nitrogen content and $N$-doped graphite in yielding of acetophenone (Table 6).

Very recently, Yao et al. [151] reported the synthesis of three novel catalysts (CuPp, MnPp, and $\mathrm{ZnPp}$ ) by solvothermal methods and measured their catalytic activity in terms of alkylbenzene conversion. The catalysts exhibited better activities for ethylbenzene oxidation and selectivity towards acetophenone. These catalysts can be recycled by simple 
filtration with no loss of catalytic ability and selectivity. Among these three catalysts, MnPp showed the highest catalytic ability and the selectivity (99\%). Although the conversion rates of $\mathrm{CoPp}$ and $\mathrm{CuPp}$ catalysts were slightly lower, the selectivity exceeded more than $98 \%$. On the other hand, $\mathrm{ZnPp}$ exhibited low catalytic ability in ethylbenzene conversion $(40 \%)$.

\section{Current Approach for Oxidation Reaction}

Recently, scientists are paying more attention to use the catalysts especially heterogeneous for oxidation reactions some of them have been summarized in Table 2 .

\section{Future Prospects}

Several heterogeneous metal complexes are available for the oxidation of alkylbenzenes at high temperatures $\left(>300^{\circ} \mathrm{C}\right)$, but the majority of the systems are not suitable for industrial conversions since the reactive intermediates are converted to various by-products that incur additional purification cost. Besides, the product distribution further depends on several factors. The profit-making interest in industrial catalysis of ethylbenzene to carbonyl compounds is a priori and must receive due interest in recent catalytic chemistry. The key barrier is the harsh reaction condition, and hence, designing a catalytic system with low cost and readily available selectivity has been challenging. The innovation of a novel method and modification of the existing techniques having clear advantages will continue to receive attention in catalyst research.

\section{Conclusions}

The continuous importance of aerobic oxidation of the alkyl substituted benzene to its corresponding ketone has inspired researchers to develop an efficient, green, and novel catalyst. Homogeneous catalysts have been investigated for high selectivity and conversion rate for the ethylbenzene oxidation. However, the reusable features of the supported metal catalysts have got wider acceptability even though the catalytic ability of the heterogeneous catalysts is still lower than the homogeneous ones. Lots of improvements have been made in the development of $\mathrm{SiO}_{2}-\mathrm{Al}_{2} \mathrm{O}_{3}$ - and $\mathrm{SiO}_{2}$-based catalytic system along with various metals and organic/semiorganic linkers, and the selectivity of these systems has been demonstrated with various activators as building units. The $\mathrm{Au} / \mathrm{SiO}_{2}$ systems have made numerous progresses in the aerobic oxidation of alkylbenzene. Apart from this, $\mathrm{SiO}_{2}-\mathrm{Al}_{2} \mathrm{O}_{3}$-based catalysts have presented much reactivity and selectivity in a variety of oxidation processes. Because of the substantial improvements in product yield and catalyst reusability, heterogeneous catalysts have gained growing consideration in the recent years. The wider availability along with various physical features and porosities of several supports (e.g., mesoporous carbon hydroxyapatite, mesoporous silica, and microporous zeolite) attracts think-tank to design and generate catalytic systems as well as to explore their oxidation scheme. Porous supports along with channels and welldefined cages offer a nanoreactor environment, which can present shape selectivity for substrates, products, and transition states.

\section{Conflicts of Interest}

The authors confirm that this article content has no conflicts of interest regarding the publication of the journal.

\section{Authors' Contributions}

This work was carried out in collaboration with all authors. All the authors read and approved the final manuscript.

\section{Acknowledgments}

This research was funded by the Deanship of Scientific Research at Princess Nourah bint Abdulrahman University through the Fast-track Research Funding Program.

\section{References}

[1] B. Trost, "Conprehensive organic synthesis: selectivity, strategy \& efficiency in modern organic chemistry," Pergamon Press, vol. 3, 1991.

[2] R. C. Larock, "Comprehensive organic transformations : a guide to functional group preparations," vol. 68, Article ID A86, 1999.

[3] J. K, "Industrial organic chemistry," Nature, vol. 141, no. 3561 , p. $211,1938$.

[4] T. Mehler, W. Behnen, J. Wilken, and J. Martens, "Enantioselective catalytic reduction of acetophenone with borane in the presence of cyclic $\alpha$-amino acids and their corresponding $\beta$ amino alcohols," Tetrahedron: Asymmetry, vol. 5, no. 2, pp. 185-188, 1994.

[5] R. T. Blickenstaff, W. R. Hanson, S. Reddy, and R. Witt, "Potential radioprotective agents-VI. Chalcones, benzophenones, acid hydrazides, nitro amines and chloro compounds. Radioprotection of murine intestinal stem cells," Bioorganic \& Medicinal Chemistry, vol. 3, no. 7, pp. 917-922, 1995.

[6] M. E. Ali, M. M. Rahman, and S. B. A. Hamid, "Nanoclustered gold: a promising green catalysts for the oxidation of alkyl substituted benzenes," Advanced Materials Research, vol. 925, pp. 38-42, 2014.

[7] G. R. Newkome and D. L. Fishel, "Preparation of hydrazones: acetophenone hydrazone," in Organic Syntheses, p. 102, John Wiley \& Sons, Inc, Hoboken, NJ, USA, 2003.

[8] S. L. Regen and C. Koteel, "Activation through impregnation. Permanganate-coated solid supports," Journal of the American Chemical Society, vol. 99, no. 11, pp. 3837-3838, 1977.

[9] F. M. Menger and C. Lee, "Synthetically useful oxidations at solid sodium permanganate surfaces," Tetrahedron Letters, vol. 22, no. 18, pp. 1655-1656, 1981.

[10] J. R. Holum, "Study of the chromium(VI) oxide-pyridine complex," The Journal of Organic Chemistry, vol. 26, no. 12, pp. 4814-4816, 1961.

[11] G. Cainelli and G. Cardillo, Chromium oxidations in organic chemistry; reactivity and structure concepts in organic chemistry, vol. 19, Springer Berlin Heidelberg, Berlin, Heidelberg, 1984. 
[12] D. G. Lee and U. A. Spitzer, "aqueous dichromate oxidation of primary alcohols," The Journal of Organic Chemistry, vol. 35, no. 10, pp. 3589-3590, 1970.

[13] J. Muzart, "Chromium-catalyzed oxidations in organic synthesis," Chemical Reviews, vol. 92, no. 1, pp. 113-140, 1992.

[14] A. Dijksman, A. Marino-González, A. M. i. Payeras, I. W. C. E. Arends, and R. A. Sheldon, "Efficient and selective aerobic oxidation of alcohols into aldehydes and ketones using ruthenium/TEMPO as the catalytic system," Journal of the American Chemical Society, vol. 123, no. 28, pp. 68266833, 2001.

[15] W. P. Griffith, "Ruthenium oxo complexes as organic oxidants," Chemical Society Reviews, vol. 21, no. 3, p. 179, 1992.

[16] A. J. Mancuso and D. Swern, "Activated dimethyl sulfoxide: useful reagents for synthesis," Synthesis, vol. 1981, no. 3, pp. 165-185, 1981.

[17] D. B. Dess and J. C. Martin, "Readily accessible 12-I-5 oxidant for the conversion of primary and secondary alcohols to aldehydes and ketones," The Journal of Organic Chemistry, vol. 48, no. 22, pp. 4155-4156, 1983.

[18] W. P. Griffith, S. V. Ley, G. P. Whitcombe, and A. D. White, "Preparation and use of tetra-n-butylammonium perruthenate (TBAP reagent) and tetra-n-propylammonium per-ruthenate (TPAP reagent) as new catalytic oxidants for alcohols," Journal of the Chemical Society, Chemical Communications, no. 21, p. 1625, 1987.

[19] M. Hudlicky, "Oxidations in organic chemistry," American Chemical Society, vol. 186, p. 433, 1990.

[20] M. Hudlicky, "Oxidations in organic chemistry," vol. 28, Choice Reviews Online, USA, 1991.

[21] A. Demirbas, "Biodiesel production via non-catalytic SCF method and biodiesel fuel characteristics," Energy Conversion and Management, vol. 47, no. 15-16, pp. 2271-2282, 2006.

[22] B.-Z. Zhan and A. Thompson, "Recent developments in the aerobic oxidation of alcohols," Tetrahydron, vol. 60, no. 13, pp. 2917-2935, 2004.

[23] A. V. Biradar and T. Asefa, "Nanosized gold-catalyzed selective oxidation of alkyl-substituted benzenes and $n$-alkanes," Applied Catalysis A: General, vol. 435-436, pp. 19-26, 2012.

[24] C. K. P. Neeli, A. Narani, R. K. Marella, K. S. Rama Rao, and D. R. Burri, "Selective benzylic oxidation of alkylaromatics over Cu/SBA-15 catalysts under solvent-free conditions," Catalysis Communications, vol. 39, pp. 5-9, 2013.

[25] N. K. Mal and A. V. Ramaswamy, "Oxidation of ethylbenzene over Ti-, V- and Sn-containing silicalites with MFI structure," Applied Catalysis A: General, vol. 143, no. 1, pp. 75-85, 1996.

[26] N. Anand, K. H. P. Reddy, G. V. S. Prasad, K. S. Rama Rao, and D. R. Burri, "Selective benzylic oxidation of alkyl substituted aromatics to ketones over Ag/SBA-15 catalysts," Catalysis Communications, vol. 23, pp. 5-9, 2012.

[27] Z. Zhuang, S. A. Giles, J. Zheng et al., "Nickel supported on nitrogen-doped carbon nanotubes as hydrogen oxidation reaction catalyst in alkaline electrolyte," Nature Communications, vol. 7, no. 1, p. 10141, 2016.

[28] D. Habibi and A. R. Faraji, "Synthesis, characterization and application of a nano-manganese-catalyst as an efficient solid catalyst for solvent free selective oxidation of ethylbenzene, cyclohexene, and benzylalcohol," Applied Surface Science, vol. 276, pp. 487-496, 2013.

[29] M. Arshadi, M. Ghiaci, A. A. Ensafi, H. Karimi-Maleh, and S. L. Suib, "Oxidation of ethylbenzene using some recyclable cobalt nanocatalysts: the role of linker and electrochemical study," Journal of Molecular Catalysis A: Chemical, vol. 338, pp. 71-83, 2011.

[30] M. E. Ali, M. M. Rahman, S. M. Sarkar, and S. B. A. Hamid, "Heterogeneous metal catalysts for oxidation reactions," Journal of Nanomaterials, vol. 2014, Article ID 192038, 23 pages, 2014.

[31] J. R. H. Ross, "Heterogeneous catalysis-chemistry in two dimensions," in Heterogeneous Catalysis, pp. 1-15, 2012.

[32] X. Jin, J. Feng, S. Li et al., "A novel homogeneous catalysisliquid/solid separation system for highly effective recycling of homogeneous catalyst based on a phosphine- functionalized polyether guanidinium ionic liquid," Molecular Catalysis, vol. 475, p. 110503, 2019.

[33] I. Fechete, Y. Wang, and J. C. Védrine, "The past, present and future of heterogeneous catalysis," Catalysis Today, vol. 189, no. 1, pp. 2-27, 2012.

[34] D. J. Cole-Hamilton, "Homogeneous catalysis-new approaches to catalyst separation, recovery, and recycling," Science, vol. 299, no. 5613, pp. 1702-1706, 2003.

[35] M. A. M. Hossain, M. E. Ali, S. B. Abd Hamid, and M. M. Rahman, "Catalytic oxidation of alkyl benzene," Advances in Materials Research, vol. 1109, pp. 248-252, 2015.

[36] S. Dan-Hua, J. Lin-Tao, L. Zhi-Gang, S. Wen-Bin, and G. Can-Cheng, "Ethylbenzene oxidation over hybrid metalloporphyrin@silica nanocomposite microspheres," Journal of Molecular Catalysis A: Chemical, vol. 379, pp. 15-20, 2013.

[37] P. Karthikeyan, P. R. Bhagat, and S. S. Kumar, "A novel, green 1-glycyl-3-methyl imidazolium chloride-copper(II) complex catalyzed C-H oxidation of alkyl benzene and cyclohexane," Chinese Chemical Letters, vol. 23, no. 6, pp. 681-684, 2012.

[38] G. L. Song, Y. Y. Liu, L. Chen, and H. J. Zhu, "Selective oxidation of alkyl benzenes using $\mathrm{CrO}_{3}$ combined with $\mathrm{Ce}\left(\mathrm{SO}_{4}\right)_{2}$," Asian Journal of Chemistry, vol. 22, pp. 7267-7274, 2010.

[39] S. Yamazaki, "Chromium(VI) oxide-catalyzed benzylic oxidation with periodic acid," Organic Letters, vol. 1, no. 13, pp. 2129-2132, 1999.

[40] S. Habibzadeh and M. Tajbakhsh, "Oxidation of alkyl benzenes to corresponding carbonyl compounds with 1,4dichloro-1,4-diazoniabicyclo [2,2,2] octane bis-chloride in water," Journal of Chemical Research, vol. 2009, no. 11, pp. 696-698, 2009.

[41] A. J. Catino, J. M. Nichols, H. Choi, S. Gottipamula, and M. P. Doyle, "Benzylic oxidation catalyzed by dirhodium(II,III) caprolactamate," Organic Letters, vol. 7, no. 23, pp. 51675170, 2005.

[42] A. T. Khan, T. Parvin, L. H. Choudhury, and S. Ghosh, "A simple synthetic protocol for oxidation of alkyl-arenes into ketones using a combination of $\mathrm{HBr}-\mathrm{H}_{2} \mathrm{O}_{2}$," Tetrahedron Letters, vol. 48, no. 13, pp. 2271-2274, 2007.

[43] A. Shaabani, E. Farhangi, and A. Rahmati, "Aerobic oxidation of alkyl arenes and alcohols using cobalt(II) phthalocyanine as a catalyst in 1-butyl-3-methyl-imidazolium bromide," Applied Catalysis A: General, vol. 338, no. 1-2, pp. 14-19, 2008.

[44] M. Arshadi and M. Ghiaci, "Highly efficient solvent free oxidation of ethylbenzene using some recyclable catalysts: the role of linker in competency of manganese nanocatalysts," Applied Catalysis A: General, vol. 399, no. 1-2, pp. 75-86, 2011. 
[45] D. Habibi, A. R. Faraji, M. Arshadi, H. Veisi, and A. Gil, "Manganese nanocatalyst and N-hydroxyphthalimide as an efficient catalytic system for selective oxidation of ethylbenzene, cyclohexene and oximes under aerobic condition," Journal of Molecular Catalysis A: Chemical, vol. 382, pp. 41-54, 2014.

[46] M. Arshadi, M. Ghiaci, A. Rahmanian, H. Ghaziaskar, and A. Gil, "Oxidation of ethylbenzene to acetophenone by a $\mathrm{Mn}$ catalyst supported on a modified nanosized $\mathrm{SiO}_{2} / \mathrm{Al}_{2} \mathrm{O}_{3}$ mixed-oxide in supercritical carbon dioxide," Applied Catalysis B: Environmental, vol. 119-120, pp. 81-90, 2012.

[47] D. Habibi, A. R. Faraji, M. Arshadi, and J. L. G. Fierro, "Characterization and catalytic activity of a novel Fe nano-catalyst as efficient heterogeneous catalyst for selective oxidation of ethylbenzene, cyclohexene, and benzylalcohol," Journal of Molecular Catalysis A: Chemical, vol. 372, pp. 90-99, 2013.

[48] D. Habibi, A. R. Faraji, M. Arshadi, S. Heydari, and A. Gil, "Efficient catalytic systems based on cobalt for oxidation of ethylbenzene, cyclohexene and oximes in the presence of N-hydroxyphthalimide," Applied Catalysis A: General, vol. 466, pp. 282-292, 2013.

[49] D. Habibi and A. R. Faraji, "Preparation, characterization and catalytic activity of a nano-Co(II)-catalyst as a high efficient heterogeneous catalyst for the selective oxidation of ethylbenzene, cyclohexene, and benzyl alcohol," Comptes Rendus Chimie, vol. 16, no. 10, pp. 888-896, 2013.

[50] S. Mobini, F. Meshkani, and M. Rezaei, "Supported Mn catalysts and the role of different supports in the catalytic oxidation of carbon monoxide," Chemical Engineering Science, vol. 197, pp. 37-51, 2019.

[51] C. Papadopoulos, K. Kappis, J. Papavasiliou et al., "Copperpromoted ceria catalysts for CO oxidation reaction," Catalysis Today, 2019.

[52] P. A. DeSario, C. L. Pitman, D. J. Delia et al., "Low-temperature $\mathrm{CO}$ oxidation at persistent low-valent $\mathrm{Cu}$ nanoparticles on $\mathrm{TiO}_{2}$ aerogels," Applied Catalysis B: Environmental, vol. 252, pp. 205-213, 2019.

[53] G. Spezzati, A. D. Benavidez, A. T. DeLaRiva et al., "CO oxidation by Pd supported on $\mathrm{CeO}_{2}(100)$ and $\mathrm{CeO}_{2}(111)$ facets," Applied Catalysis B: Environmental, vol. 243, pp. 36-46, 2019.

[54] C. Li, X. Yang, G. Gao et al., "Copper on the inner surface of mesoporous TiO2hollow spheres: a highly selective photocatalyst for partial oxidation of methanol to methyl formate," Catalysis Science \& Technology, vol. 9, no. 22, pp. 62406252, 2019.

[55] A. El Roz, P. Fongarland, F. Dumeignil, and M. Capron, "Glycerol to glyceraldehyde oxidation reaction over Ptbased catalysts under base-free conditions," Frontiers in Chemistry, vol. 7, pp. 1683-1690, 2019.

[56] Y. Yang, J. Liu, Z. Wang et al., "A complete catalytic reaction scheme for $\mathrm{Hg}^{0}$ oxidation by $\mathrm{HCl}$ over $\mathrm{RuO}_{2} / \mathrm{TiO}_{2}$ catalyst," Journal of Hazardous Materials, vol. 373, pp. 660-670, 2019.

[57] Y. Boyjoo, G. Rochard, J. M. Giraudon, J. Liu, and J. F. Lamonier, "Mesoporous $\mathrm{MnO}_{2}$ hollow spheres for enhanced catalytic oxidation of formaldehyde," Sustainable Materials and Technologies, vol. 20, p. e00091, 2019.

[58] F. Yu, D. Poole III, S. Mathew et al., "Control over electrochemical water oxidation catalysis by preorganization of molecular ruthenium catalysts in self-assembled nanospheres," Angewandte Chemie International Edition, vol. 57, no. 35, pp. 11247-11251, 2018.
[59] A. H. Hussein, A. Khalil, M. Jahjah et al., "Catalytic properties of various oxides and mesoporous materials containing niobium and sulfate ions, in the oxidation reaction of 1-octanol," International Journal of Organic Chemistry, vol. 8, no. 1, pp. 41-53, 2018.

[60] B. Qiu, D. Xu, Q. Sun et al., "Highly enantioselective oxidation of spirocyclic hydrocarbons by bioinspired manganese catalysts and hydrogen peroxide," ACS Catalysis, vol. 8, no. 3, pp. 2479-2487, 2018.

[61] S. Sadula and B. Saha, "Aerobic oxidation of xylose to xylaric acid in water over pt catalysts," ChemSusChem, vol. 11, no. 13, pp. 2124-2129, 2018.

[62] S. Khare, P. Shrivastava, R. Chokhare, J. S. Kirar, and S. Parashar, "Catalytic liquid phase oxidation of cyclohexane with tert-butylhydroperoxide over transition metal exchanged $\alpha$-zirconium phosphate," Indian Journal of Chemical Technology-Section A, vol. 57A, pp. 427-434, 2018.

[63] R. Rizo, D. Sebastián, M. J. Lázaro, and E. Pastor, "On the design of Pt-Sn efficient catalyst for carbon monoxide and ethanol oxidation in acid and alkaline media," Applied Catalysis B: Environmental, vol. 200, pp. 246-254, 2017.

[64] Y. Kim, H. W. Kim, S. Lee et al., "The role of ruthenium on carbon-supported PtRu catalysts for electrocatalytic glycerol oxidation under acidic conditions," ChemCatChem, vol. 9, no. 9, pp. 1683-1690, 2017.

[65] L. Li, Q. Yang, S. Chen et al., "Boosting selective oxidation of cyclohexane over a metal-organic framework by hydrophobicity engineering of pore walls," Chemical Communications, vol. 53, no. 72, pp. 10026-10029, 2017.

[66] X. Lin, S. Zhao, L. Fu, Y. Luo, R. Zhu, and Z. Liu, "Synthesis of Co-N-C grafted on well-dispersed $\mathrm{MnO}_{x}-\mathrm{CeO}_{2}$ hollow mesoporous sphere with efficient catalytic performance," Molecular Catalysis, vol. 437, pp. 18-25, 2017.

[67] A. De Clercq, O. Margeat, G. Sitja, C. R. Henry, and S. Giorgio, "Core-shell Pd-Pt nanocubes for the CO oxidation," Journal of Catalysis, vol. 336, pp. 33-40, 2016.

[68] S. Y. Hwang, E. Yurchekfrodl, C. Zhang, and Z. Peng, "Lowtemperature preferential oxidation of carbon monoxide on Pt3Ni alloy nanoparticle catalyst with engineered surface," ChemCatChem, vol. 8, no. 1, p. 3, 2016.

[69] M. Witek, M. D. Koppang, and G. M. Swain, "Aliphatic polyamine oxidation reaction mechanism at boron-doped microcrystalline and ultrananocrystalline diamond electrodes," Electroanalysis, vol. 28, no. 1, pp. 151-160, 2016.

[70] B.-D. Hong, K.-L. Hunag, H.-R. Chen, and C.-L. Lee, "Effect of defective graphene flake for catalysts of supported Pd nanocubes toward glucose oxidation reaction in alkaline medium," Journal of the Electrochemical Society, vol. 163, no. 9, pp. H731-H737, 2016.

[71] Y. Chen, M. Cui, S. Li et al., "The influence of potential scanning rate on the electrocatalytic activity of pyrolysis-treated $\mathrm{PdO} /$ graphene for ethanol oxidation reaction (EOR)," International Journal of Electrochemical Science, pp. 3285-3295, 2016.

[72] A. Ejaz, M. S. Ahmed, and S. Jeon, "Synergistic effect of 1,4-benzenedimethaneamine assembled graphene supported palladium for formaldehyde oxidation reaction in alkaline media," Journal of the Electrochemical Society, vol. 163, no. 5, pp. B163-B168, 2016.

[73] A. B. Yousaf, M. Imran, A. Zeb et al., "Single phase PtAg bimetallic alloy nanoparticles highly dispersed on reduced 
graphene oxide for electrocatalytic application of methanol oxidation reaction," Electrochimica Acta, vol. 197, pp. 117-125, 2016.

[74] C. Alegre, M. Gálvez, R. Moliner, and M. Lázaro, "Influence of the synthesis method for Pt catalysts supported on highly mesoporous carbon xerogel and Vulcan carbon black on the electro-oxidation of methanol," Catalysts, vol. 5, no. 1, pp. 392-405, 2015.

[75] C. D. Evans, S. A. Kondrat, P. J. Smith et al., "The preparation of large surface area lanthanum based perovskite supports for AuPt nanoparticles: tuning the glycerol oxidation reaction pathway by switching the perovskite B site," Faraday Discussions, vol. 188, pp. 427-450, 2016.

[76] C.-H. Kuo, W. Li, L. Pahalagedara et al., "Understanding the role of gold nanoparticles in enhancing the catalytic activity of manganese oxides in water oxidation reactions," Angewandte Chemie, vol. 127, no. 8, pp. 2375-2380, 2015.

[77] K. Mandal, D. Bhattacharjee, P. S. Roy, S. K. Bhattacharya, and S. Dasgupta, "Room temperature synthesis of $\mathrm{Pd}-\mathrm{Cu}$ nanoalloy catalyst with enhanced electrocatalytic activity for the methanol oxidation reaction," Applied Catalysis A: General, vol. 492, pp. 100-106, 2015.

[78] A. Ghorbani-Choghamarani, Z. Darvishnejad, and M. Norouzi, " $\mathrm{Cu}(\mathrm{II})$-Schiff base complex-functionalized magnetic Fe3O4nanoparticles: a heterogeneous catalyst for various oxidation reactions," Applied Organometallic Chemistry, vol. 29, no. 3, pp. 170-175, 2015.

[79] P. Mukherjee, P. S. Roy, K. Mandal, D. Bhattacharjee, S. Dasgupta, and S. K. Bhattacharya, "Improved catalysis of room temperature synthesized $\mathrm{Pd}-\mathrm{Cu}$ alloy nanoparticles for anodic oxidation of ethanol in alkaline media," Electrochimica Acta, vol. 154, pp. 447-455, 2015.

[80] S. Lai, C. Fu, Y. Chen et al., "Pt-content-controlled synthesis of Pd nanohollows/Pt nanorods core/shell composites with enhanced electrocatalytic activities for the methanol oxidation reaction," Journal of Power Sources, vol. 274, pp. 604610, 2015.

[81] L. Wang, D. Yang, J. Wang, Z. Zhu, and K. Zhou, “Ambient temperature CO oxidation over gold nanoparticles (14 nm) supported on $\mathrm{Mg}(\mathrm{OH})_{2}$ nanosheets," Catalysis Communications, vol. 36, pp. 38-42, 2013.

[82] I. V. Delidovich, B. L. Moroz, O. P. Taran et al., “Aerobic selective oxidation of glucose to gluconate catalyzed by $\mathrm{Au} / \mathrm{Al}_{2} \mathrm{O}_{3}$ and $\mathrm{Au} / \mathrm{C}$ : impact of the mass-transfer processes on the overall kinetics," Chemical Engineering Journal, vol. 223, pp. 921-931, 2013.

[83] H. Zhang and N. Toshima, "Synthesis of Au/Pt bimetallic nanoparticles with a Pt-rich shell and their high catalytic activities for aerobic glucose oxidation," Journal of Colloid and Interface Science, vol. 394, pp. 166-176, 2013.

[84] H. Wang, W. Fan, Y. He, J. Wang, J. N. Kondo, and T. Tatsumi, "Selective oxidation of alcohols to aldehydes/ketones over copper oxide- supported gold catalysts," Journal of Catalysis, vol. 299, pp. 10-19, 2013.

[85] M. Zhang, X. Zhu, X. Liang, and Z. Wang, "Preparation of highly efficient $\mathrm{Au} / \mathrm{C}$ catalysts for glucose oxidation via novel plasma reduction," Catalysis Communications, vol. 25, pp. 92-95, 2012.

[86] P. Bujak, P. Bartczak, and J. Polanski, "Highly efficient roomtemperature oxidation of cyclohexene and d-glucose over nanogold $\mathrm{Au} / \mathrm{SiO}_{2}$ in water," Journal of Catalysis, vol. 295, pp. 15-21, 2012.
[87] W. Li, A. Wang, X. Liu, and T. Zhang, "Silica-supported $\mathrm{Au}-\mathrm{Cu}$ alloy nanoparticles as an efficient catalyst for selective oxidation of alcohols," Applied Catalysis A: General, vol. 433434, pp. 146-151, 2012.

[88] G. Zhan, Y. Hong, V. T. Mbah et al., "Bimetallic Au-Pd/MgO as efficient catalysts for aerobic oxidation of benzyl alcohol: A green bio-reducing preparation method," Applied Catalysis A: General, vol. 439-440, pp. 179-186, 2012.

[89] Z. Zhang, L. Xin, K. Sun, and W. Li, "Pd-Ni electrocatalysts for efficient ethanol oxidation reaction in alkaline electrolyte," International Journal of Hydrogen Energy, vol. 36, no. 20, pp. 12686-12697, 2011.

[90] M. M. Tusi, N. S. O. Polanco, S. G. da Silva, E. V. Spinacé, and A. O. Neto, "The high activity of $\mathrm{PtBi} / \mathrm{C}$ electrocatalysts for ethanol electro-oxidation in alkaline medium," Electrochemistry Communications, vol. 13, no. 2, pp. 143-146, 2011.

[91] S. Y. Shen, T. S. Zhao, and J. B. Xu, "Carbon-supported bimetallic PdIr catalysts for ethanol oxidation in alkaline media," Electrochimica Acta, vol. 55, no. 28, pp. 9179-9184, 2010.

[92] R. F. B. Souza De, M. M. Tusi, M. Brandalise et al., "Preparation of $\mathrm{PtSn} / \mathrm{C}-\mathrm{Rh}$ and $\mathrm{PtSn} / \mathrm{C}-\mathrm{CeO}_{2}$ for ethanol electro-oxidation," International Journal of Electrochemical Science, vol. 5, pp. 895-902, 2010.

[93] T. Ishida, S. Okamoto, R. Makiyama, and M. Haruta, "Aerobic oxidation of glucose and 1-phenylethanol over gold nanoparticles directly deposited on ion-exchange resins," Applied Catalysis A: General, vol. 353, no. 2, pp. 243-248, 2009.

[94] T. Mitsudome, A. Noujima, T. Mizugaki, K. Jitsukawa, and K. Kaneda, "Supported gold nanoparticle catalyst for the selective oxidation of silanes to silanols in water," Chemical Communications, no. 35, pp. 5302-5304, 2009.

[95] Q. Jiang, Y. Xiao, Z. Tan, Q.-H. Li, and C.-C. Guo, “Aerobic oxidation of $p$-xylene over metalloporphyrin and cobalt acetate: Their synergy and mechanism," Journal of Molecular Catalysis A: Chemical, vol. 285, no. 1-2, pp. 162-168, 2008.

[96] X. Yang, X. Wang, C. Liang et al., "Aerobic oxidation of alcohols over $\mathrm{Au} / \mathrm{TiO}_{2}$ : an insight on the promotion effect of water on the catalytic activity of $\mathrm{Au} / \mathrm{TiO}_{2}$," Catalysis Communications, vol. 9, no. 13, pp. 2278-2281, 2008.

[97] H. Li, B. Guan, W. Wang et al., "Aerobic oxidation of alcohol in aqueous solution catalyzed by gold," Tetrahedron, vol. 63, no. 35, pp. 8430-8434, 2007.

[98] K. M. Parida and D. Rath, "Structural properties and catalytic oxidation of benzene to phenol over $\mathrm{CuO}$ - impregnated mesoporous silica," Applied Catalysis A: General, vol. 321, no. 2, pp. 101-108, 2007.

[99] T. Hayashi, T. Inagaki, N. Itayama, and H. Baba, "Selective oxidation of alcohol over supported gold catalysts: methyl glycolate formation from ethylene glycol and methanol," Catalysis Today, vol. 117, no. 1-3, pp. 210-213, 2006.

[100] B. Guan, D. Xing, G. Cai et al., "Highly selective aerobic oxidation of alcohol catalyzed by a gold(I) complex with an anionic ligand," Journal of the American Chemical Society, vol. 127, no. 51, pp. 18004-18005, 2005.

[101] E. M. Flanigen, J. M. Bennett, R. W. Grose et al., "Silicalite, a new hydrophobic crystalline silica molecular sieve," Nature, vol. 271, no. 5645, pp. 512-516, 1978.

[102] R. Ciriminna, V. Pandarus, F. Béland, Y.-J. Xu, and M. Pagliaro, "Heterogeneously catalyzed alcohol oxidation 
for the fine chemical industry," Organic Process Research \& Development, vol. 19, no. 11, pp. 1554-1558, 2014.

[103] J. S. Reddy, S. Sivasanker, and P. Ratnasamy, "Hydroxylation of phenol over TS-2, a titanium silicate molecular sieve," Journal of Molecular Catalysis, vol. 71, no. 3, pp. 373-381, 1992.

[104] M. Ghiaci, F. Molaie, M. E. Sedaghat, and N. Dorostkar, "Metalloporphyrin covalently bound to silica. Preparation, characterization and catalytic activity in oxidation of ethyl benzene," Catalysis Communications, vol. 11, no. 8, pp. 694-699, 2010.

[105] F. Rajabi, R. Luque, J. H. Clark, B. Karimi, and D. J. Macquarrie, "A silica supported cobalt (II) Salen complex as efficient and reusable catalyst for the selective aerobic oxidation of ethyl benzene derivatives," Catalysis Communications, vol. 12, no. 6, pp. 510-513, 2011.

[106] L. Chen, B.-D. Li, Q.-X. Xu, and D.-B. Liu, "A silica gel supported cobalt(II) Schiff base complex as efficient and recyclable heterogeneous catalyst for the selective aerobic oxidation of alkyl aromatics," Chinese Chemical Letters, vol. 24, no. 9, pp. 849-852, 2013.

[107] S. S. Bhoware, S. Shylesh, K. R. Kamble, and A. P. Singh, "Cobalt-containing hexagonal mesoporous molecular sieves (Co-HMS): synthesis, characterization and catalytic activity in the oxidation reaction of ethylbenzene," Journal of Molecular Catalysis A: Chemical, vol. 255, no. 1-2, pp. 123-130, 2006.

[108] Sujandi, E. A. Prasetyanto, D.-S. Han, S.-C. Lee, and S.-E. Park, "Immobilization of $\mathrm{Co}(\mathrm{III})$ using tethered cyclam ligand on SBA-15 mesoporous silica for aerial oxidation of ethylbenzene," Catalysis Today, vol. 141, no. 3-4, pp. 374-377, 2009.

[109] A. R. Faraji, F. Ashouri, Z. Hekmatian, S. Heydari, and S. Mosazadeh, "Organosuperbase dendron manganese complex grafted on magnetic nanoparticles; heterogeneous catalyst for green and selective oxidation of ethylbenzene, cyclohexene and oximes by molecular oxygen," Polyhedron, vol. 157, pp. 90-106, 2019.

[110] S. L. H. Rebelo, M. M. Q. Simões, M. G. P. M. S. Neves, and J. A. S. Cavaleiro, "Oxidation of alkylaromatics with hydrogen peroxide catalysed by manganese(III) porphyrins in the presence of ammonium acetate," Journal of Molecular Catalysis A: Chemical, vol. 201, no. 1-2, pp. 9-22, 2003.

[111] A. Thellend, P. Battioni, and D. Mansuy, "Ammonium acetate as a very simple and efficient cocatalyst for manganese porphyrin-catalysed oxygenation of hydrocarbons by hydrogen peroxide," Journal of the Chemical Society, Chemical Communications, no. 9, p. 1035, 1994.

[112] P. Battioni, J. P. Renaud, J. F. Bartoli, M. Reina-Artiles, M. Fort, and D. Mansuy, "Monooxygenase-like oxidation of hydrocarbons by hydrogen peroxide catalyzed by manganese porphyrins and imidazole: selection of the best catalytic system and nature of the active oxygen species," Journal of the American Chemical Society, vol. 110, no. 25, pp. 8462-8470, 1988.

[113] A. M. d.' A. Rocha Gonsalves and A. C. Serra, "On the mechanism of carboxylic acid co-catalyst assisted metalloporphyrin oxidations," Journal of Molecular Catalysis A: Chemical, vol. 168, no. 1-2, pp. 25-32, 2001.

[114] T.-C. Zheng and D. E. Richardson, "Manganese porphyrin catalyzed homogeneous aqueous oxidation of organic molecules by magnesium monoperoxyphthalate (MMPP)," Tetrahedron Letters, vol. 36, no. 6, pp. 837-840, 1995.

[115] K. Xavier, J. Chacko, and K. Mohammed Yusuff, “Zeoliteencapsulated $\mathrm{Co}(\mathrm{II}), \mathrm{Ni}(\mathrm{II})$ and $\mathrm{Cu}(\mathrm{II})$ complexes as catalysts for partial oxidation of benzyl alcohol and ethylbenzene," Applied Catalysis A: General, vol. 258, no. 2, pp. 251-259, 2004.

[116] V. R. Choudhary, J. R. Indurkar, V. S. Narkhede, and R. Jha, "MnO4-1 exchanged $\mathrm{Mg}$-Al hydrotalcite: a stable and reusable/environmental- friendly catalyst for selective oxidation by oxygen of ethylbenzene to acetophenone and diphenylmethane to benzophenone," Journal of Catalysis, vol. 227, no. 1, pp. 257-261, 2004.

[117] T. H. Bennur, D. Srinivas, and S. Sivasanker, "Oxidation of ethylbenzene over "neat" and zeolite-Y-encapsulated copper tri- and tetraaza macrocyclic complexes," Journal of Molecular Catalysis A: Chemical, vol. 207, no. 2, pp. 163-171, 2004.

[118] S. K. Jana, P. Wu, and T. Tatsumi, "NiAl hydrotalcite as an efficient and environmentally friendly solid catalyst for solvent-free liquid-phase selective oxidation of ethylbenzene to acetophenone with $1 \mathrm{~atm}$ of molecular oxygen," Journal of Catalysis, vol. 240, no. 2, pp. 268-274, 2006.

[119] T. Radhika and S. Sugunan, "Vanadia supported on ceria: characterization and activity in liquid-phase oxidation of ethylbenzene," Catalysis Communications, vol. 8, no. 2, pp. 150-156, 2007.

[120] X. G. Li, J. Wang, and R. He, "Selective oxidation of ethylbenzene catalyzed by fluorinated metalloporphyrins with molecular oxygen," Chinese Chemical Letters, vol. 18, no. 9, pp. 1053-1056, 2007.

[121] H. Ma, J. Xu, Q. Zhang, H. Miao, and W. Wu, "Selective oxidation of ethylbenzene by a biomimetic combination: Hemin and N-hydroxyphthalimide (NHPI)," Catalysis Communications, vol. 8, no. 1, pp. 27-30, 2007.

[122] G. Raju, P. S. Reddy, J. Ashok, B. M. Reddy, and A. Venugopal, "Solvent-free aerobic oxidation of ethylbenzene over supported $\mathrm{Ni}$ catalysts using molecular oxygen at atmospheric pressure," Journal of Natural Gas Chemistry, vol. 17, no. 3, pp. 293-297, 2008.

[123] C. Ngamcharussrivichai, P. Wu, and T. Tatsumi, "Liquidphase Beckmann rearrangement of cyclohexanone oxime over mesoporous molecular sieve catalysts," Journal of Catalysis, vol. 227, no. 2, pp. 448-458, 2004.

[124] T. Ushikubo and K. Wada, "Vapor-phase Beckmann rearrangement over silica-supported tantalum oxide catalysts," Journal of Catalysis, vol. 148, no. 1, pp. 138-148, 1994.

[125] I. Murwani, K. Scheurell, and E. Kemnitz, "Liquid phase oxidation of ethylbenzene on pure and metal doped $\mathrm{HS}-\mathrm{AlF}_{3}$," Catalysis Communications, vol. 10, no. 2, pp. 227-231, 2008.

[126] M. Salavati-Niasari, "Host (nanocavity of zeolite-Y)/guest $\left(\left[\mathrm{Cu}([\mathrm{R}])_{2}-\mathrm{N}_{2} \mathrm{X}_{2}\right)\right]_{2}+\left(\mathrm{R}=\mathrm{H}, \mathrm{CH}_{3} ; \mathrm{X}=\mathrm{NH}, \mathrm{O}, \mathrm{S}\right)$ nanocomposite materials: synthesis, characterization and catalytic oxidation of ethylbenzene," Journal of Molecular Catalysis A: Chemical, vol. 284, no. 1-2, pp. 97-107, 2008.

[127] M. Ghiaci, Z. Sadeghi, M. E. Sedaghat, H. Karimi-Maleh, J. Safaei-Ghomi, and A. Gil, "Preparation of Pd (0) and Pd (II) nanotubes and nanoparticles on modified bentonite and their catalytic activity in oxidation of ethyl benzene to acetophenone," Applied Catalysis A: General, vol. 381, no. 1-2, pp. 121-131, 2010.

[128] K. George and S. Sugunan, "Nickel substituted copper chromite spinels: preparation, characterization and catalytic activity in the oxidation reaction of ethylbenzene," Catalysis Communications, vol. 9, no. 13, pp. 2149-2153, 2008.

[129] T. Iwahama, G. Hatta, S. Sakaguchi, and Y. Ishii, "Epoxidation of alkenes using alkyl hydroperoxides generated in situ 
by catalytic autoxidation of hydrocarbons with dioxygen," Chemical Communications, no. 2, pp. 163-164, 2000.

[130] Y. Ishii, S. Sakaguchi, and T. Iwahama, "Innovation of hydrocarbon oxidation with molecular oxygen and related reactions," Advanced Synthesis and Catalysis, vol. 343, no. 5, pp. 393-427, 2001.

[131] Y. Yoshino, Y. Hayashi, T. Iwahama, S. Sakaguchi, and Y. Ishii, "Catalytic oxidation of alkylbenzenes with molecular oxygen under normal pressure and temperature byNHydroxyphthalimide combined with $\mathrm{Co}(\mathrm{OAc})_{2}$," The Journal of Organic Chemistry, vol. 62, no. 20, pp. 6810-6813, 1997.

[132] A. Shibamoto, S. Sakaguchi, and Y. Ishii, "Aerobic oxidation of methylpyridines to pyridinecarboxylic acids catalyzed byN-Hydroxyphthalimide," Organic Process Research \& Development, vol. 4, no. 6, pp. 505-508, 2000.

[133] G. Zheng, C. Liu, Q. Wang, M. Wang, and G. Yang, "Metalfree: an efficient and selective catalytic aerobic oxidation of hydrocarbons with oxime andN-Hydroxyphthalimide," Advanced Synthesis and Catalysis, vol. 351, no. 16, pp. 2638-2642, 2009.

[134] G. Yang, Y. Ma, and J. Xu, "Biomimetic catalytic system driven by electron transfer for selective oxygenation of hydrocarbon," Journal of the American Chemical Society, vol. 126, no. 34, pp. 10542-10543, 2004.

[135] X. Tong, J. Xu, and H. Miao, "Highly efficient and metal-free aerobic hydrocarbons oxidation process by anophenanthroline-mediated organocatalytic system," Advanced Synthesis and Catalysis, vol. 347, no. 15, pp. 1953-1957, 2005.

[136] O. Fukuda, S. Sakaguchi, and Y. Ishii, “A new strategy for catalytic Baeyer-Villiger oxidation of KA-oil with molecular oxygen using $\mathrm{N}$-hydroxyphthalimide," Tetrahedron Letters, vol. 42, no. 20, pp. 3479-3481, 2001.

[137] S. Sakaguchi, T. Hirabayashi, and Y. Ishii, "First Ritter-type reaction of alkylbenzenes using $\mathrm{N}$-hydroxyphthalimide as a key catalyst," Chemical Communications, no. 5, pp. 516-517, 2002.

[138] X. Yang, L. Zhou, Y. Chen et al., “A promotion effect of alkaline-earth chloride on N-hydroxyphthalimide- catalyzed aerobic oxidation of hydrocarbons," Catalysis Communications, vol. 11, no. 3, pp. 171-174, 2009.

[139] F. Minisci, F. Recupero, C. Gambarotti, C. Punta, and R. Paganelli, "Selective functionalisation of hydrocarbons by nitric acid and aerobic oxidation catalysed by $\mathrm{N}$ hydroxyphthalimide and iodine under mild conditions," Tetrahedron Letters, vol. 44, no. 36, pp. 6919-6922, 2003.

[140] S. Sakaguchi, Y. Nishiwaki, T. Kitamura, and Y. Ishii, "Efficient catalytic alkane nitration with $\mathrm{NO}_{2}$ under air assisted by N-hydroxyphthalimide," Angewandte Chemie International Edition, vol. 40, no. 1, pp. 222-224, 2001.

[141] K. Matsunaka, T. Iwahama, S. Sakaguchi, and Y. Ishii, "A remarkable effect of quaternary ammonium bromide for the $N$-hydroxyphthalimide-catalyzed aerobic oxidation of hydrocarbons," Tetrahedron Letters, vol. 40, no. 11, pp. 2165-2168, 1999.

[142] J. Qin, F. Zaihui, Y. Liu et al., "Aerobic Oxidation of Ethylbenzene Co-catalyzed by $N$-Hydroxyphthalimide and Oxobis(8-Quinolinolato) Vanadium (IV) Complexes," Chinese Journal of Catalysis, vol. 32, no. 6-8, pp. 1342-1348, 2011.

[143] B. Gao, Y. Li, and N. Shi, "Oxovanadium (IV) Schiff base complex immobilized on CPS microspheres as heterogeneous catalyst for aerobic selective oxidation of ethyl benzene to acetophenone," Reactive and Functional Polymers, vol. 73, no. 11, pp. 1573-1579, 2013.

[144] J. Luo, H. Yu, H. Wang, and F. Peng, "Enhancing the catalytic activity of carbon nanotubes by filled iron nanowires for selective oxidation of ethylbenzene," Catalysis Communications, vol. 51, pp. 77-81, 2014.

[145] Z. Miao, H. Zhao, J. Yang, J. Zhao, H. Song, and L. Chou, "Facile synthesis of ordered mesoporous $\mathrm{Cu}-\mathrm{ZrPO}$ with high copper contents as catalyst for liquid phase oxidation of ethylbenzene," Microporous and Mesoporous Materials, vol. 198, pp. 271-280, 2014.

[146] G. Li, Y. Li, R. Mu, Y. Xu, and P. Dong, "Direct side-chain oxidation of ethylbenzene over supported Co4HP2Mo15V3O62 catalysts as a clean and highly efficient approach to producing acetophenone," Reaction Kinetics, Mechanisms and Catalysis, vol. 109, no. 1, pp. 199-212, 2013.

[147] C. Guo, Q. Peng, Q. Liu, and G. Jiang, "Selective oxidation of ethylbenzene with air catalyzed by simple $\mu$-oxo dimeric metalloporphyrins under mild conditions in the absence of additives," Journal of Molecular Catalysis A: Chemical, vol. 192, no. 1-2, pp. 295-302, 2003.

[148] A. R. Faraji, S. Mosazadeh, and F. Ashouri, "Synthesis and characterization of cobalt-supported catalysts on modified magnetic nanoparticle: green and highly efficient heterogeneous nanocatalyst for selective oxidation of ethylbenzene, cyclohexene and oximes with molecular oxygen," Journal of Colloid and Interface Science, vol. 506, pp. 10-26, 2017.

[149] J. Luo, F. Peng, H. Yu, H. Wang, and W. Zheng, “Aerobic liquid-phase oxidation of ethylbenzene to acetophenone catalyzed by carbon nanotubes," ChemCatChem, vol. 5, no. 6, pp. 1578-1586, 2013.

[150] W. F. Xu, W. J. Chen, D. C. Li, B. H. Cheng, and H. Jiang, "Highly dispersed manganese based Mn/N-C/Al2O3Catalyst for selective oxidation of the $\mathrm{C}-\mathrm{H}$ bond of ethylbenzene," Industrial and Engineering Chemistry Research, vol. 58, no. 10, pp. 3969-3977, 2019.

[151] Y. Yao, Y. Du, J. Li, C. Wang, Z. Zhang, and X. Zhao, "Crystal structure ofmeso-substituted pyrazolyl porphyrin complexes and their highly active catalyst for oxidation of alkylbenzenes," Applied Organometallic Chemistry, vol. 32, no. 3, article e4184, 2018

[152] P. Tang, Y. Gao, J. Yang, W. Li, H. Zhao, and D. Ma, “Growth mechanism of $\mathrm{N}$-doped graphene materials and their catalytic behavior in the selective oxidation of ethylbenzene," Chinese Journal of Catalysis, vol. 35, no. 6, pp. 922-928, 2014.

[153] Y. Gao, G. Hu, J. Zhong et al., "Nitrogen-doped SP $^{2}$-hybridized carbon as a superior catalyst for selective oxidation," Angewandte Chemie International Edition, vol. 52, no. 7, pp. 2109-2113, 2013. 